Portland State University

PDXScholar

6-9-2021

\title{
E(Raced): Race and Use of Self Amongst BIPOC Social Workers
}

Anita Reinette Gooding

Portland State University

Follow this and additional works at: https://pdxscholar.library.pdx.edu/open_access_etds

Part of the Gender, Race, Sexuality, and Ethnicity in Communication Commons, Race and Ethnicity Commons, and the Social Work Commons Let us know how access to this document benefits you.

\section{Recommended Citation}

Gooding, Anita Reinette, "E(Raced): Race and Use of Self Amongst BIPOC Social Workers" (2021). Dissertations and Theses. Paper 5702.

https://doi.org/10.15760/etd.7574

This Dissertation is brought to you for free and open access. It has been accepted for inclusion in Dissertations and Theses by an authorized administrator of PDXScholar. Please contact us if we can make this document more accessible: pdxscholar@pdx.edu. 
E(Raced): Race and Use of Self Amongst BIPOC Social Workers

by

Anita Reinette Gooding

A dissertation submitted in partial fulfillment of the requirements for the degree of

Doctor of Philosophy

in

Social Work and Social Research

Dissertation Committee:

Gita R. Mehrotra, Chair

Lakindra Mitchell Dove

Stephanie A. Bryson

Miriam J. Abelson

Portland State University

2021 
(C) 2021 Anita Reinette Gooding 


\begin{abstract}
Use of self is defined as the social worker's instrument, and involves an intentional engagement of one's personhood in ways that facilitate client change (Heyt \& Sherman, 2005). This dissertation argues that race is one component of the social worker's self that is visible, and that can affect how Black, Indigenous, and People of Color (BIPOC) social workers use self in their practice. Using Critical Race Theory, Social Identity Theory and an Interpretive Description methodology, this dissertation engages 27 BIPOC field instructors in semi-structured interviews in order to answer the following research questions: a) What are the components of use of self, as defined by BIPOC social workers?; b) How have they used self in practice and to what effect?; c) How do issues of race and racism affect their perceptions of using self in practice contexts? Findings indicate that for BIPOC social workers, self-disclosure, bringing one's whole self, and race are components of use of self, and they used these factors to model change, affirm the effects of race on the client experience, and to deepen their relationships with clients. Findings also show that race and racism affected perceptions of using self because participant bodies were stereotyped and they faced heightened scrutiny in their work. Lastly, agency culture affected use of self - when in an affirming agency participants felt comfortable using self but when in a non-inclusive environment, they were less likely to use self to the benefit of their practice. Study findings have implications for practice, research and social work education and highlight social work's need to: a) include race and other identity categories into conversations about use of self; b) include conversations about agency context as it informs how (and whether) social workers use
\end{abstract}


self in practice; and lastly c) include lessons on self-disclosure as a tool to move the change process and worker-client relationship forward. 
Dedication

To the social workers I interviewed who shared their stories and insights in the hopes of creating a more equitable future for social work. I see you and I appreciate you. 
Acknowledgements

I would like to thank my parents, Patricia and Edward, who always believed education was a path to liberation and my mother in particular for all of her hard work to raise three amazing women. To my sisters, Ria and Nicole, who have never hesitated to remind me of roots. I also could not have done this without my wife Ryan who has walked alongside me the entire way. I also must mention my kiddo, Marley, who offered laughter, kisses, and much-needed distractions during the hardest parts of this process.

I would also like to express my sincerest gratitude to my chair, Dr. gita mehrotra who has mentored me from the start of my doctoral program and will continue to mentor me for as long as she'll have me! It has been an honor to know you. I also am deeply grateful to every member of my committee; each one added invaluable perspectives to this project: Dr. Bryson for her clinical and critical mind, Dr. Mitchell Dove for her practice wisdom, and Dr. Abelson who provided a vital connection to my first academic love - women, gender, and sexuality studies.

Last, but not least, I would like to thank the many colleagues, faculty, staff, and friends who rooted for me the entire way and always believed this was possible. I carry you all with me. 
TABLE OF CONTENTS

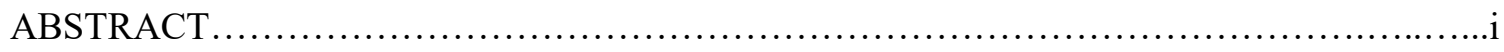

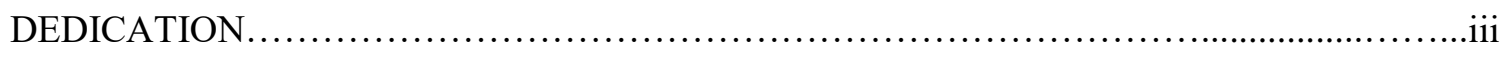

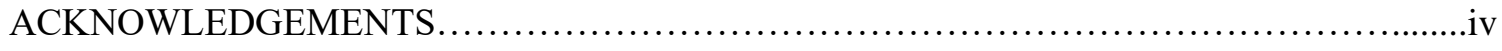

LIST OF TABLES ........................................................... vii

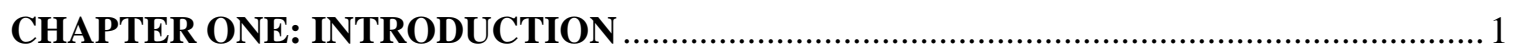

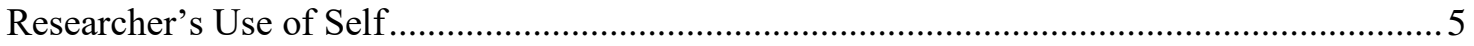

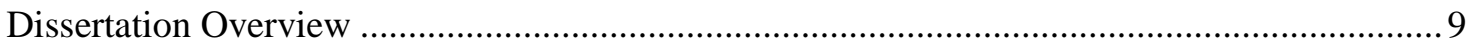

CHAPTER TWO: LITERATURE REVIEW AND THEORETICAL FRAMEWORKS .... 12

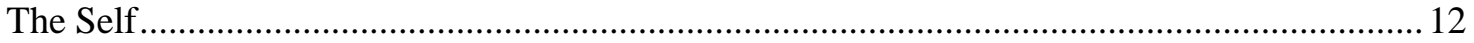

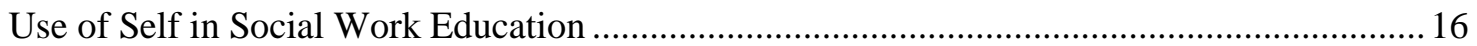

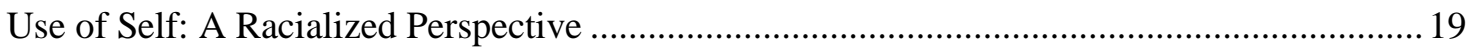

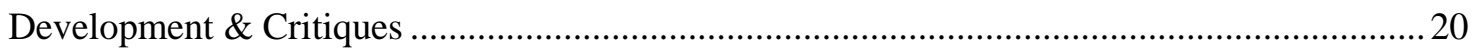

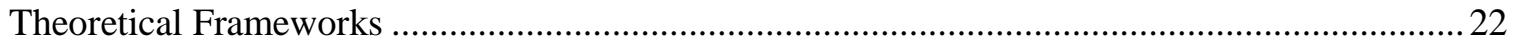

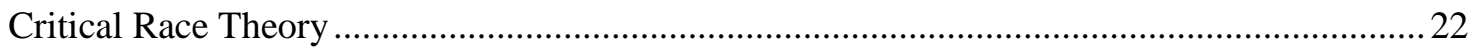

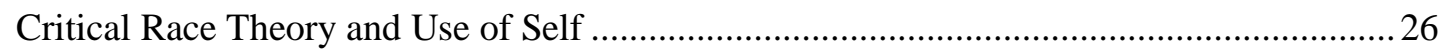

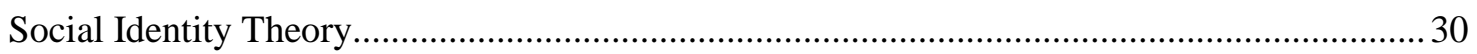

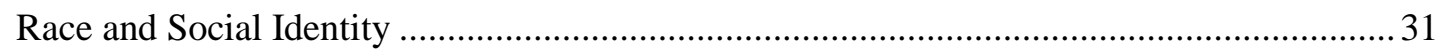

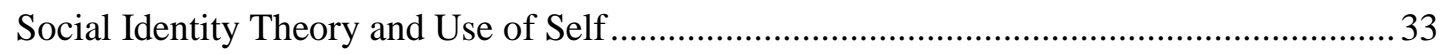

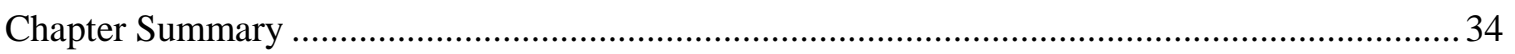

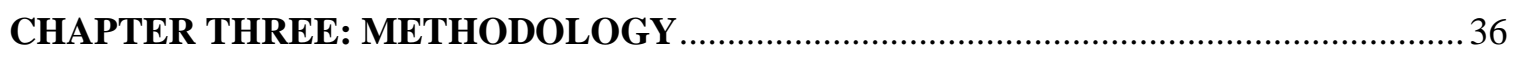

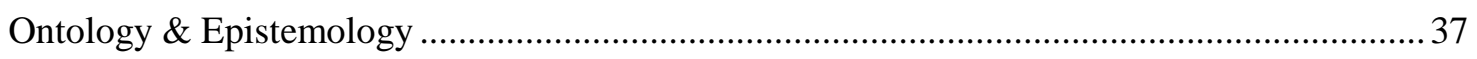

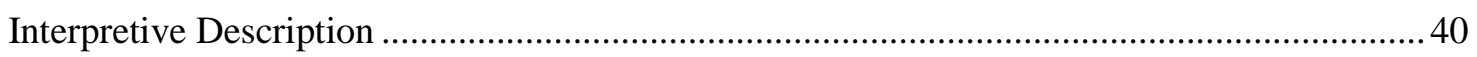

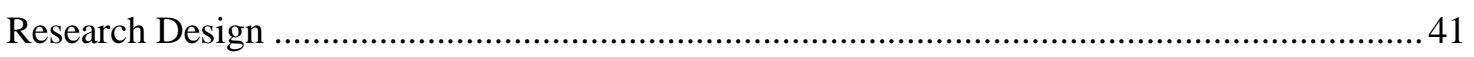

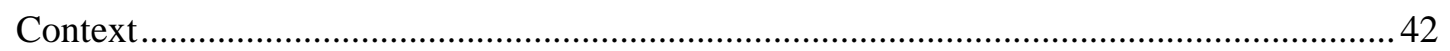

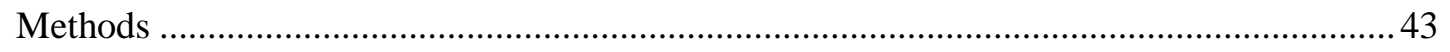

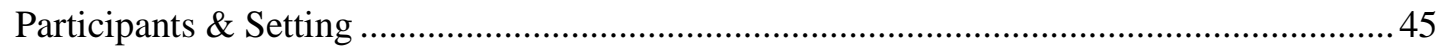

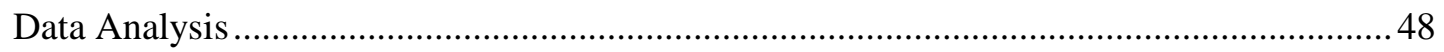

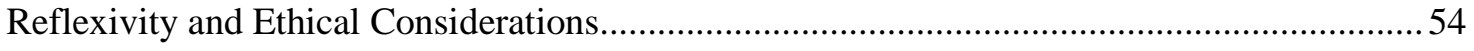

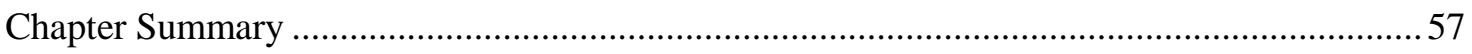

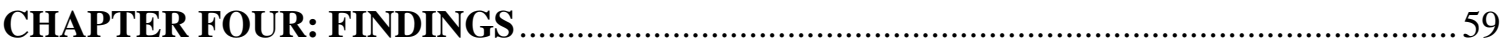

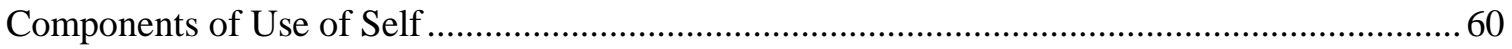




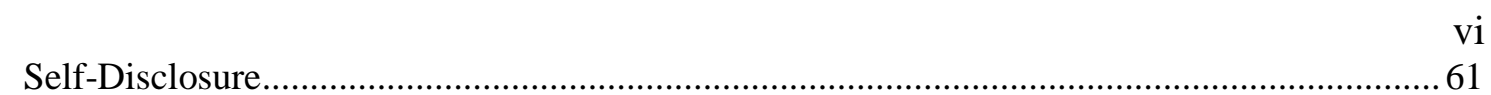

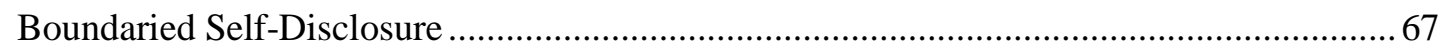

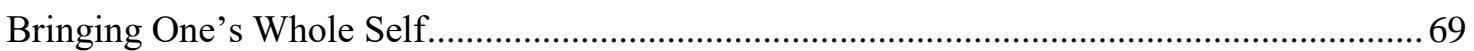

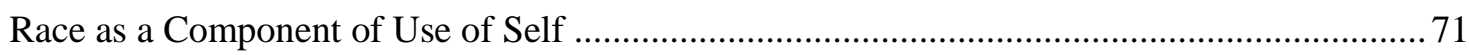

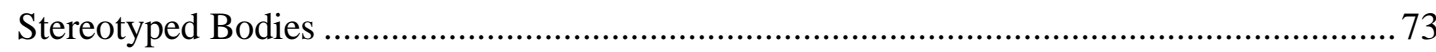

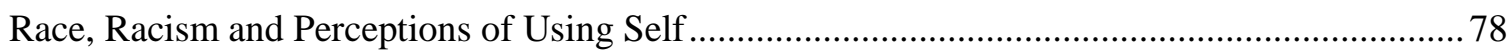

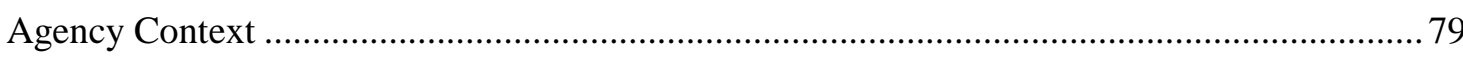

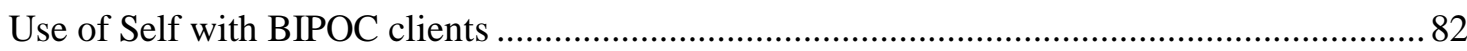

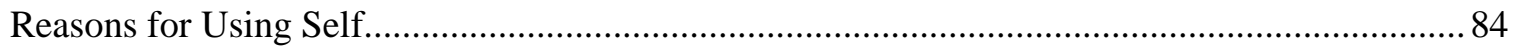

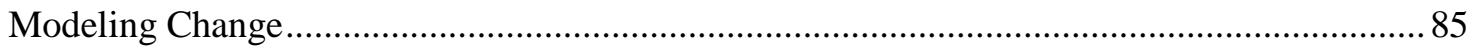

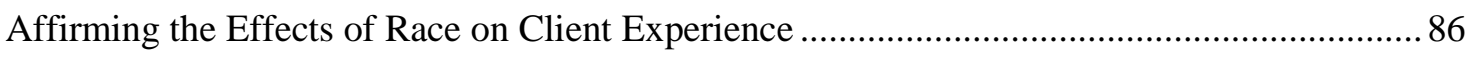

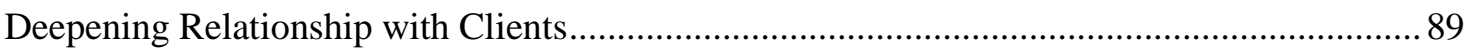

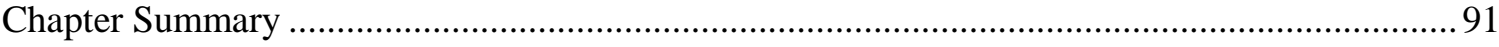

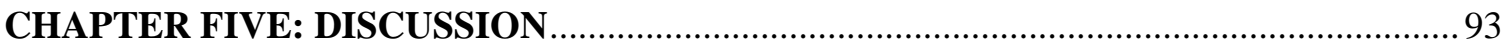

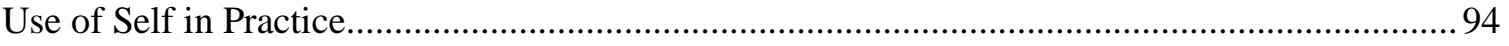

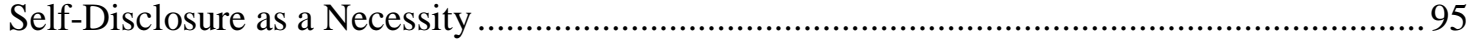

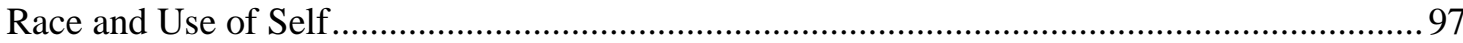

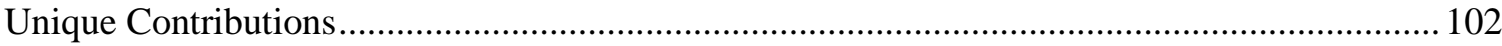

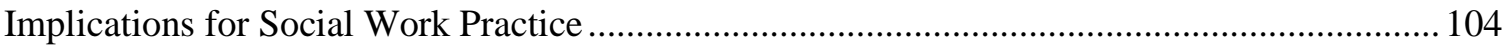

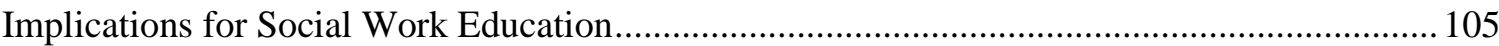

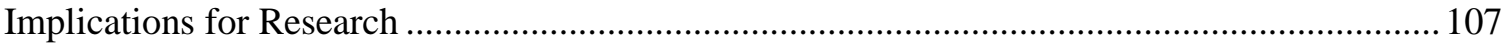

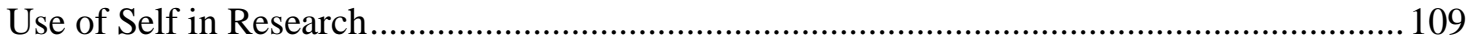

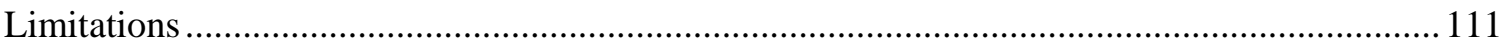

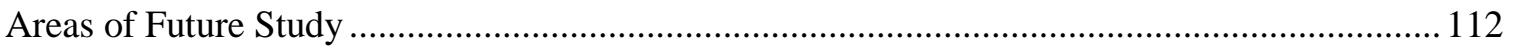

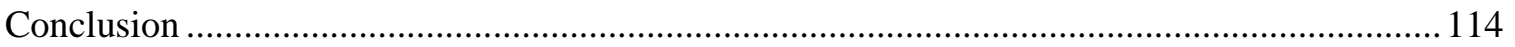

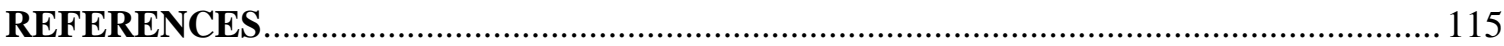

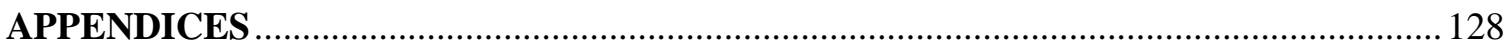

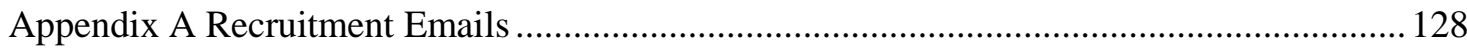

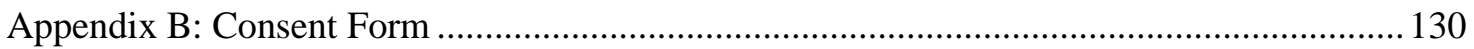

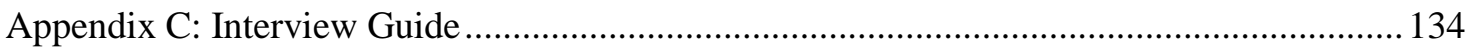

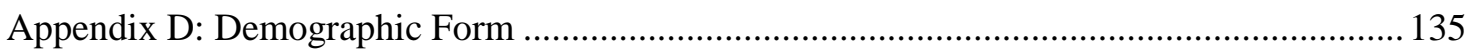




\section{LIST OF TABLES}

Table 1: Participant Demographics................................................46

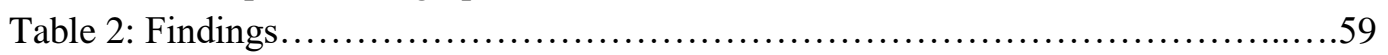




\section{CHAPTER ONE: INTRODUCTION}

If we begin our analysis from, and limit it to, the space of

privileged communities, our visions of justice are more

likely to be exclusionary because privilege nurtures

blindness to those without the same privileges (Mohanty,

2000, p. 407).

The United States is rapidly becoming more racially diverse. A recent report by the United States Census (2018) projects that by 2030, population growth for nonHispanic Whites will decrease. In its stead, the fastest growing population will be biracial and multiracial persons followed by Hispanics and Asians. In addition, by 2060, the number of foreign-born individuals will increase from $14 \%$ of the population to $17 \%$. The social work profession increasingly reflects the diversity of the general population. In fact, $45.4 \%$ of Bachelor of Social Work (BSW) and $41.3 \%$ of Master of Social Work (MSW) students are from historically underrepresented racial groups (CSWE, 2017). Despite this increasing demographic of people of color, social work curricula for practice courses still center those who hold dominant identities and whose ideas are rooted within dominant narratives on social life. Scholars have noted that the practice methods and theories taught in social work education are most often based upon the assumptions of dominant, Eurocentric culture, and if not questioned, these assumptions are then applied to non-dominant groups (Ortiz \& Jani, 2010). Furthermore, social work curricular content often assumes students are White. 
In their latent analysis of social justice curricula from 27 social work programs in the United States, Mehrotra, Hudson \& Self (2019) found that a key assumption of MSW diversity and social justice classes was that social workers were from dominant identity groups, and their service users were not. For instance, course descriptions positioned marginalized groups as 'other,' and did not challenge or discuss dominant identities like Whiteness or maleness. Badwall (2015) also contends that Whiteness is so embedded within social work identity, values, and knowledges that many racialized social workers doubt their professional abilities, and/or have others question their skills. This doubt begins in the classroom when lessons on working with diverse clients assumes that the practitioner is White, and does not explore or name what it means to experience racism while practicing social work as a racialized person. Badwall (2015) continues:

Racialized workers cannot be seen as liberal, moral subjects when racism is named, as the very naming of racism disrupts both the ideals of the profession and the neoliberal underpinnings of the state. Being seen as moral subjects requires an erasure of race, which is impossible for racialized people (p. 19)

In other words, because social work centers Whiteness, the field struggles to accept that race and racism is central to the practice experience of BIPOC social workers. Thus, when social work content erases the practice insights and knowledges held by marginalized groups - that race is a part of practice - it hides perspectives that may provide a more nuanced societal view. 
Unfortunately, what society considers knowledge often depends upon what 'experts' (who hold power and privilege) deem valuable (Collins, 2000; Janack, 1997); thus, centering dominant discourses illuminates issues of epistemic privilege and authority. Epistemic privilege relates to whose knowledge is recognized as valid and whose is suppressed (Janack, 1997). Within social work education specifically, one can easily see epistemic privilege in action when we look at the canonical authors referenced in practice courses and see predominantly White men - ex: Sigmund Freud, Aaron Beck, Alfred Bandura and Erik Erikson.

Epistemic authority on the other hand, confers privilege to "those who have and use (or are used by others who have) the opportunity to be known as authorities, and in being known as authorities, become privileged to speak further" (Hesse-Biber, 2014, p. 21). Those who hold epistemic authority have the chance to be studied by scholars, and their experiences understood. Epistemic authority and epistemic privilege connect in research when those who hold dominant identities easily see themselves reflected in the research, and the knowledge created from that research is upheld as accurate and, even considered generalizable. As a result, the perspectives and insights of non-dominant racial groups are hidden.

The following dissertation hopes to highlight what Michel Foucault (1977) calls subjugated knowledges; differential knowledges that have always been present, yet are not considered scientific or logical enough for the mainstream. Collins (2000) advances that for Black feminists, their experiences hold key subjugated knowledges that are generated as a result of a lifetime of social subordination. This study hopes to uplift the 
voices of social workers of color as treasure troves of knowledge, and through examining use of self within the practice experiences of racialized peoples, I hope to bring their subjugated knowledges to the forefront of social work understandings of use of self.

Use of self describes social workers' intentional exercising of their "motivation and capacity to communicate and interact with others in ways that facilitate change" (Sheafor \& Horejsi, 2003, p. 69). In other words, it is how social workers selectively use aspects of self as a tool for client growth and change; these tools include personality, selfdisclosure, and application of theory to practice (Reupert, 2007). Yet, even though we know that race affects social work practice, it has not been considered a component of use of self.

In one of the few social work articles to consider the implications of race in professional social work practice from a non-dominant perspective, Ashley, SantacruzCervantes \& Karnsomprot Castro (2016) share their experience doing transdisciplinary social work as women of color. In spite of their initial excitement, the transdisciplinary meetings quickly became tense, and one of the authors shared the rejection she felt when her $20+$ years of practice insights were ignored around a particular client case. She states: I felt that my years of experience and recommendations were ignored by my teammates in lieu of others who seemed to have little insight into this case. My professional pride was bruised and my personal self was hurt and enraged. Painful questions surfaced in the back of my mind. I wondered if my expertise was viewed as 
insignificant next to my White counterparts. While I knew I

was the most competent one on the team to address these

concerns, it seemed that the team didn't realize or respect

that. I tried to rationalize that they were ignorant regarding

the role of social workers, but their outright dismissal of

my input gnawed at me (p.11).

The authors' experience highlights how race can affect the way one is perceived and thus, the way they use self. As much as the authors tried to "communicate and interact with others in ways that facilitate change" (Sheafor \& Horejsi, 2003 p. 69), race stood in the way. Since use of self is a tool for social work practice (Heydt \& Sherman, 2005), an examination of use of self from a Black, Indigenous, and People of Color (BIPOC) perspective offers an opening into how race may affect a practitioner's understanding of the construct in their practice, and their ability to use who they are to facilitate client change.

\section{Researcher's Use of Self}

We are not suggesting that a researcher impose...[their] experience upon the data. Rather, we want to use our experiences to bring up other possibilities of meaning (Corbin \& Strauss, 2008, p. 80)

A traditional modernist and positivist approach believes that people in 'objective' positions (code for those with dominant identities and narratives), can see the world as it is because they are not clouded by things like emotion and religion. Hence, truth is 
uncovered by holding values separate from facts (Janack, 1997). In contrast, I believe that values are inherently embedded within the research process, and therefore objectivity is impossible; instead, we learn about the world around us, and develop our 'truths' based on subjective experience. For this reason, it is important to share how I came to study race and use of self.

A few months after completing my MSW degree, I began working full-time at an HIV/AIDS organization where I provided treatment education for those living with HIV/AIDS. At the same time, I worked part-time as a therapist at a local LGBTQ organization. The demographics of both spaces were vastly different. At my full-time job, approximately $90 \%$ of service users identified as Black/African American with the remaining identifying as Latinx, White, Mixed Race or Other. Alternatively, in the behavioral health wing of the LGBTQ organization, approximately 70 percent of clients identified as White with Black/African American being the largest racial minority group (though I never had a Black person as a client) and others identifying as Latinx, Asian or Other. During my time in both spaces I quickly learned that because my race is one visible aspect of who I am, it contributed to the ways in which I used self both consciously and unconsciously.

As a Black woman, I found that when my race aligned with that of a service user at my full-time job, the relationship seemed to progress quickly. Because we both navigated the world as the same race, we could more easily converse about race, and do so in advanced ways; we implicitly trusted the other person understood the racialized experience. For instance, while having a conversation with a Black trans woman who was 
navigating suicidal thoughts, she talked about her experience dating and surviving on the streets. While she spoke, I could immediately consider how race factored into her experience so that when she eventually mentioned race, we were both aware of the myriad of ways it could (and did) complicate her life. My assumption is that our ability to 'bypass' race ultimately served to help facilitate client change because of the trust we developed and our shared identities. As a result, she was able to be vulnerable about her needs and desires, which made it easier for us to work together to develop a safety plan for her suicidal ideation.

Other participants would also share a life experience and say things like, "Well, you know what I mean" or "It's nice to have a Black person here." I felt they trusted me enough to be vulnerable around race. Of course, just because we shared the same race did not mean our experiences were the same. In addition, I did not instantly connect with every Black service user. However, I found that for the most part, our shared racial identity made the relationship feel mutually meaningful. It felt as though through connecting around our racial identities, we were developing solidarity on behalf of the larger Black community as a whole. In this way, race factored into my use of self because it helped me build relationships, and trust, with clients who shared my racial identity.

My second anecdotal experience around race and use of self occurred in my parttime work as a therapist. All of my clients identified as White, and while working with a White trans male on his grief, he shared some of his experiences dating. He noted in earlier sessions that the last and only person he truly dated was a Black man. Their relationship was not a positive experience for him for a myriad of reasons. Yet, for some 
reason in that particular session he talked about his relationship and ended by saying, "I don't have anything against Black people, you know." I honestly do not remember how I responded, just that we talked about his comment for a few minutes after. However, the fact that I do not remember my response indicates just how surprised I was by his statement - surprised that it came up seemingly out of context. In that instant, I immediately understood that race was a factor in our relationship all along.

Through the process of being raced in session I understood that I was not just a social worker in his eyes but a Black social worker, and my race represented multiple things outside of myself. I understood that in spite of using humor, self-disclosure, and other use of self tools to build rapport, race remained a component of how he viewed me. As a result, I felt guarded, judged, and unable to be 'authentic,' which is one component of use of self (Dewane, 2006). Race then became countertransferential, in that I projected my anxieties onto him. In that moment my self-confidence was affected, and I worried race would impede my ability to facilitate change as he moved through his grief work.

These two experiences helped me see the ways race could factor into use of self in practice contexts. Additionally, they illustrated how racial dynamics could help or hinder relationship building, which is important in order for client change to occur. My practice experiences, along with the dearth of social work practice literature from BIPOC perspectives, motivate me to research use of self from the perspectives of BIPOC social workers because I believe their insights are vital to the conversation. Furthermore, my insights will allow me to explore different possibilities (Corbin and Strauss, 2008), such 
as the ways use of self and meaning-making about this concept may vary intra and interracially.

\section{Dissertation Overview}

This dissertation explores the following research questions:

- What are the components of use of self, as defined by BIPOC social workers?

- How have they used self in their practice and to what effect?

- How do issues of race and racism affect their perceptions of using self in practice contexts?

To answer these questions, I conducted qualitative interviews with 27 BIPOC-

identified practicing social workers who have served (or can serve) as field instructors to social work students. I believe that field instructors were the perfect sub-sect of practitioners to interview because they are connected to social work education through the students they supervise, and they are also connected to the practice field through their employment. In this way, field instructors help move the social work profession forward. Additionally, field instructors are always thinking and observing practice due to their supervisory role with students, which allow for particularly useful insights about use of self in practice. They were asked directly about how and why they use self, as well as their practice experience navigating race and racism around use of self. Interviews were recorded, transcribed and analyzed using an interpretive description methodology.

Throughout the following chapters, the terms therapist and worker are used interchangeably to refer to social work practitioners. Since use of self is most often found 
in the clinical literature, these terms reflect the language used in this body of scholarship. Second, the term 'client' refers to individuals accessing services from a social worker. These individuals may also be referred to as service users. Third, BIPOC, social workers of color, and racialized peoples are used interchangeably to refer to racial minorities within the United States. These groups include those who identify as any of the following: African American/Black/of the African Diaspora, Asian/Asian American, South Asian, West Asian/Arab/Middle Eastern, Pacific Islander, First Nations/Alaskan Native/Native American/Indigenous, Chicanx/Latinx, and/or Multiracial/Mixed-Race people. I specifically use BIPOC to speak to the unique relationship Indigenious and Black peoples hold to Whiteness; a relationship which has shaped how other people of color are perceived and treated in the United States (BIPOC project, n.d., para 2).

My research was conducted within a predominantly White city in a predominantly White state. Therefore, my sample includes a variety of racial and ethnic groups. A key benefit of a culturally diverse sample is that it simultaneously allows for a close look at how use of self differs across racial groups, while it also maintains a broader exploratory lens about how race affects use of self across racialized groups.

Lastly, since race and racial dynamics in the United States frame the present research, it is important to acknowledge how I define race. I use Haney-Lopez's (1994) definition which holds that races are:

....a vast group of people loosely bound together by historically contingent, socially significant elements of their morphology and/or ancestry...social meanings connect 
our faces to our souls...as used here, the referents of terms

like Black and White are social groups, not genetically distinct branches of mankind. Note that Whites exist as a race under this definition. It is not only people of color who find their identities mediated by race, or who are implicated in the building and maintenance of racial constructs ( $\mathrm{p}$. 193).

Haney-Lopez's (1994) definition of race serves this study because it acknowledges a shared experience of systemic racism and I would add, a shared experience of resistance to racism and oppression. Additionally, this definition recognizes race as a social construct informed by history and power relations, not biology.

This proposed dissertation contains five chapters in order to delve deeply into race and use of self in social work. The next chapter provides an overview of the scholarly literature on use of self, and reviews Critical Race Theory and Social Identity Theory as it relates to this work. In Chapter 3 I highlight my ontological and epistemological position, and outline the methodology and study design for this research. Chapter 4 centers research findings, and the dissertation concludes with Chapter 5, a discussion of findings and implications for social work, including directions for future research. 


\section{CHAPTER TWO: LITERATURE REVIEW AND THEORETICAL FRAMEWORKS}

Use of self has a long history across disciplines - including social work, psychology, counseling and family therapy. Additionally, Critical Race Theory (CRT) and Social Identity Theory (SIT) are widely known and referenced across disciplines. Therefore, this literature review does not aim to be comprehensive, but to highlight the key conceptualizations that shape my thinking about race and use of self, such as how I

am defining self, the background and origins of use of self, and an overview of CRT and SIT. In essence, this literature review hopes to answer why race should matter to the way the social work profession understands use of self and its components. But first, who is the self?

\section{The Self}

Baldwin (1987) states that the ancients believed the self was the soul, and the soul, the essence of man. By the time Plato and Aristotle came to be, the soul was viewed as separate from the body. Descartes took discussions of self further when he claimed,'I think, therefore I am." The Cartesian frame thus separated the subjective inner world from the seemingly objective outer one. Since then, philosophers have continued to debate ideas about the self (Baldwin, 1987)

For the purposes of this dissertation, I hold that self (of both client and worker) is "dialogic, contextualized, decentered, and multiple" (Ganzer, 2007, p. 117). Stated more clearly, 'self' is not a static entity, but is formed through a relationship between the subject (self) and others (Miehls \& Moffatt, 2000, p. 342). In addition, notions of self are 
shaped through social and cultural understandings (Gordon \& Dunworth, 2017), therefore the ways we understand ourselves will always be "fluid, partial and incomplete" (p. 599), and cannot be viewed outside sociocultural factors.

Since self is formed through interaction and cannot be viewed outside society and culture, then it is possible for the self of the client and the self of the worker to influence each other (Arnd-Caddigan \& Pozzuto, 2008). As a result, there may be "structural implications with regard to racism even when one's conscious attitudes and intentions may not support racism" (Kondrat, 1999, p. 468). Stated differently, if race factors into a social worker's self-understanding (informed by society and culture), then for social workers of color, and potentially all social workers, race may be a component of use of self. As Griffith (1997) states, "the crucial question is not whether race influences the relationship between client and therapist, but under what conditions and in what way" (p. 38). For these reasons, it is necessary to explore how race impacts use of self.

Many scholars have explored race within the context of social work curricula (see: Abrams \& Moio, 2009; Chau, 1990; Dewees, 2008; Varghese, 2006), including field education (see: Amour et. al, 2004; Maidment \& Cooper, 2002; McRoy et. al, 1986; Razack, 2001). Though no studies were found that examined how race relates to use of self, the clinical literature has explored race in practice with interesting results.

Race has not been shown to affect the relationship students have with field instructors, client outcomes, or client satisfaction (Black et. al, 1997; Jones, 1978; Murphy et. al, 2004). However, race impacts how clinicians view their work. In their study, Black et. al (1997) found that field instructors who belonged to racial minority 
groups felt they were more prepared to teach students about working with diverse peoples. Similarly, students of all races who had racial minority supervisors felt better prepared to work with racial groups other than their own. Murphy et. al (2004) also concluded that therapists who shared racial identities with clients believed they were more attuned to client problems, and felt their clients were more satisfied with them. These findings indicate that race is present in the worker-client relationship, and plays a role in how social workers contextualize their practice experience.

Dewane (2006) admits that culture and ethnicity are a type of self-disclosure because “...acknowledging values emphasized in one's background or explaining cultural rituals, encourages a reach for common ground between worker and client" (p. 556). In other words, culture and ethnicity are potential components of use of self. Leary (2007) takes this a step further. She advances the idea that it is not race itself that shapes workerclient engagement, but the process of being raced, which is the codification of biological and cultural differences. In another one of her piece's Leary (1997) gives a clear example of the process of being raced and its effects on the clinical relationship:

When I work with patients of color, most of them directly acknowledge our shared racial background or shared status as members of minority groups. Many have elected to see me because I am a person of color. In due time we usually discover together the particular realities and fantasies that undergird their choice. By contrast, many of my White patients do not explicitly mention our racial difference. At 
the same time, their metaphors, allusions, and other derivatives suggest to me that it is very much on their minds - for example, in the case of a patient in consultation who repeatedly states his "ability to get along with everybody, I mean everybody" when this is ostensibly not a part of the difficulties he is trying to communicate to me. When racial similarity or difference is not mentioned during the early part of a treatment, I have found it useful to comment on this...In this way, I am offering the patient an opportunity to consider the expanded possibilities for communication provided by treatment. At the same time, I am also responding to the social milieu in which we practice. In contemporary America, race carries profound meaning (Leary, 1997, p. 164).

Leary’s (1997) example of her experiences with BIPOC and White clients, highlights both the spoken and unspoken impact of race, particularly in the United States. Given this context, it is worth researching race as an additional component of use of self. Yet presently, there remains a major gap in the literature on the intersection of race and use of self. Scholars across the fields of social work, counseling, psychology, and family therapy, have explained how to use self, debated the usefulness of the concept, and explored varying definitions of 'self;' however, few scholars have critically examined use of self through a racial lens. Specifically, how race affects use of self in social work 
practice. I believe it is vital that concepts like use of self are understood from the perspective of BIPOC social workers in order to ensure that social work embraces subjugated knowledges, and can better meet the needs of an increasingly diverse workforce.

\section{Use of Self in Social Work Education}

Heyt \& Sherman (2005) name use of self as the primary tool for social workers. As a result, students must be taught to tune their "instrument" (p. 26) in order to effectively form helping relationships. They engage with Shaefer and Horejsi's (2003) piece to suggest a number of teaching strategies for instructors to help students be more self-aware. They note instructors should: 1) encourage insight into students' personal issues; 2) discuss how student appearance connect to the first impressions clients form of their worker; 3) remind students to avoid degrading and disrespectful speech; 4) foster student awareness of their involuntary mannerisms which may distract clients; and 5) facilitate an awareness of the ways student speech, tone, and grammar could allow for clearer and more effective communication with service users. The authors argue that once students obtain self-awareness, they can "effectively engage in conscious use of self as a social worker" (p. 38). However, Reupert (2009) argues self-awareness is not enough. For students to use self effectively, they must reflect, and consider how they might use their self-awareness intentionally and professionally.

Use of self can also be used within the student-instructor dyad. Wang (2012) posits use of self as a central component of relationship building with adult learners. She holds that instructors must be aware of countertransference in the classroom, which can 
interfere with both the student's and instructor's social, emotional, and intellectual development throughout the course. Instructors must also be genuine, defined as maintaining consistent values and action, because, "who we are is as important as to our teaching as what we teach (content) and how we teach it (method)" (p. 58). Hence, use of self is a component of both social work training and practice.

Though ideas around self-awareness, reflectivity, and reflexivity are outside the scope of this dissertation, it is important to briefly distinguish my conceptualization of use of self from these other frameworks. Self-awareness simply means awareness of the present, and an ability to name one's perceptions (Kondrat, 1999). Reflectivity centers self-assessment of who one is as a person and its effects on practice (Boud, 1999; Fook, 2002; Lam et. al, 2007). Reflexivity, on the other hand, requires that practitioners selfmonitor the micro-power dynamics which exist in their interactions with clients (D'Cruz et. al, 2007).

In other words, self-awareness is about basic perceptions, reflectivity centers selfawareness for the sake of a more informed practice, while reflexivity embeds the practitioner's self-awareness within an analysis of power dynamics (Fook, 2002). Whilst self-awareness, reflectivity and reflexivity focus on the practitioner, use of self is about the client-worker dyad. Specifically, how practitioners use their understanding of who they are to affect client outcomes. Use of self is distinguishable from these other concepts because it involves purposeful and intentional use of one's personhood to influence the client (Heydt \& Sherman, 2005; Reupert, 2009). 


\section{Components of Use of Self}

Dewane (2006) operationally defines the components of use of self to be: use of personality, use of belief system, use of relational dynamics, use of anxiety, and use of self-disclosure with clients. First, use of personality involves the worker engaging in selfdiscovery in order to be as 'authentic' as possible. This 'authenticity' creates an opening for clients to do their own self-exploration. Examples of use of personality include humor and touch. Second, the use of belief systems centers the ways social workers skillfully intersect their worldview with the worldview of their client (Dewane, 2006). The balance between worker-client helps strengthen the relationship and aids the change process. Third, through relationship, the therapist and client form a "corrective emotional experience" (Alexander et al as cited in Dewane, 2006, p. 550). Thus, through therapist use of self, the client internalizes the worker, and models the connection with the worker in other relationships (Dewane, 2006). Fourth, use of anxiety is how the worker uses the anxiety produced in the therapeutic interaction to self-reflect, assess risk, and explore emotional vulnerabilities in order to best meet client needs (Dewane, 2006). Anxiety then becomes a tool for self-awareness; a self-awareness that results in better client outcomes.

Lastly, for Dewane (2006) everything can be self-disclosing, including office decor. However, when done to benefit the client, self-disclosure is a component of use of self which can further client goals. Some of the functional ways social workers apply self to practice are through relationship building, verbal self-disclosure, application of theory to practice, humor, role modeling, and lastly, statutory obligations - areas where ethical and legal issues are mediated by the worker's use of self (Reupert, 2009). 


\section{Use of Self: A Racialized Perspective}

One of the main gaps in the literature on race and use of self pertains to selfdisclosure. Self-disclosure is often referenced in the literature (eg: Anderson \& Mandell, 1989; Raines, 1996). Even more, the operational definitions of use of self - from authenticity to relationship building - all involve some form of self-disclosure. For instance, being authentic involves some level of the social worker sharing who they are with service users, and use of belief system also involves some form of disclosure. Yet, there are some aspects of self that do not need to be disclosed but still become part of the 'self' that a client sees. While a White passing BIPOC person may have the option whether to self-disclose their race or not, for social workers with a visible racialized identity, their race is instantly a part of the client experience because race is a part of social life; one that they do not have to disclose.

This key point is woefully missing from definitions of use of self. The closest article to discuss a visible identity category as it relates to use of self is Shadley's (1987) piece about using self in family therapy. One of the surprise findings was that therapists used self-disclosure differently based on gender -- male therapists highlighted the experiences of others, while female therapists were open about their particular life experiences. However, she does not explore what this means for use of self as a concept.

In her empirical study, which attempted to find a collective definition of use of self from the perspective of BSW faculty and field instructors, Liechty (2018) noted that use of self allows practitioners to engage across differences such as in culture, age and ability status but her article did not specify what that meant. She did state that 
respondents repeatedly listed use of self as a way to build the worker-client relationship. The findings indicate, "the meaning of use of self was elaborated as the ultimate integration of theory and practice embodied in the social worker and enacted in the worker-client relationship" (Liechty, 2018, p. 159).

Use of self involves the therapist feeling honest about the self they are presenting, and uplifting client needs (Arnd-Caddigan \& Pozzuto, 2007). Knowing oneself then becomes a condition for knowing others (Kaushik, 2018). However, as much as one can know themselves, we still live within a racially organized society. Therefore, an additional gap is that even though a BIPOC social worker can do their best to be selfaware when encountering a client, their racial identity still recalls to clients all the social messages and norms they received about what it means to be a BIPOC person. A quick look at the development of use of self illustrates that I am not alone in my understanding of structural oppression's impact on social work practice and use of self.

\section{Development \& Critiques}

Use of self has its roots in countertransference, a term coined by Freud to refer to a therapist projecting an emotional response onto a client. For instance, if a therapist enters a session angry because of an argument with a friend, a countertransferential response would be to project that anger onto the client. Freud believed countertransference was a barrier to treatment because it shifted focus away from the client onto the therapist's neuroses (Bernard, 2005). However, due to increased understandings of the importance of the relationship between clients and therapists in the 1950s and 60s, new ideas were introduced about the client-worker relationship; namely 
that both clients and workers had something valuable to add to the relationship and treatment.

As a result, psychotherapy transitioned from the therapist being an impartial analyst, to therapy being about two selves interacting fully. Because there were two selves, use of self became a therapeutic method for change. It opened up a path for therapists to use aspects of self, such as humor and self-disclosure, to meaningfully engage and form relationships with clients, which in turn facilitated client change (Satir, 1987).

Use of self may be facing another conceptual shift. Given its roots in countertransferential literature, and its individualistic nature, Mandell (2008) believes use of self is becoming less relevant within the social work profession because it separates individuals from the societal context; doing so facilitates a focus on individual deficits instead of the structural issues which often account for individual struggles.

Gordon \& Dunworth (2016) agree and believe the shift in how we understand use of self relates to two factors: first, social work is becoming more procedural and managerial due to an emphasis on empirically tested interventions; and, second, increasing discussions of inequality, class, and poverty require deeper analyses of power as it exists within the therapeutic relationship. Essentially, the authors believe increased procedures mean social workers are less free to use self when following scripted manuals, and use of self assumes two people interacting fully, which may not be therapeutically possible due to social inequities. 
While I agree that use of self often ignores structural inequalities - in fact, this proposed dissertation illustrates one such structural issue, race - I do not wish to get rid of the entire concept. Instead, I hope to expand our understandings of this construct. It has been consistently established in our field that in a relationship-focused profession like social work, meaningful interactions can truly make a difference to the work and to client change. Thus, my problem is not with use of self as a concept because I believe it is still relevant to social work practice. Instead, I take issue with the limited ways it has been conceptualized; namely, that race is neglected as a component of use of self. To explore this point further, the next section delves deeper into the theoretical frameworks guiding this dissertation. Specifically, it explores why race should be conceptualized as a component of use of self, and its relatedness to both the sociocultural context of race in America, as well as the interpersonal dimensions of race.

\section{Theoretical Frameworks}

Two theoretical frameworks inform the research questions guiding this study: Critical Race Theory (CRT) and Social Identity Theory (SIT). While CRT provides a macro lens to view the impacts of race on society, SIT is a micro social theory about intra- and inter-group relations. This section starts with a brief overview of both theories, then concludes with an integration of CRT and SIT as it relates to race and use of self in social work practice.

\section{Critical Race Theory}

Those of us who profess Critical Race Theory are, in simplest terms, trying to be true to ourselves. And in so 
doing, we quest more for social transformation and selfrespect than for social acceptance, scholarly citation, or in some cases, even tenure. (Calmore, 1995, p. 321)

Critical Race Theory (CRT) is an offshoot of Critical Legal Studies, which arose in the 1970s from the work of Derrick Bell, and Alan Freeman (Ladson-Billings, 1998). As legal scholars, Bell and Freeman believed that in order for racial reform to occur, the legal system needed a radical shift. Critical legal scholars analyzed the law as an artifact that maintained the U.S. class structure (Ladson-Billings, 1998), and noted that in order for racial equity to occur, the legal system needed to center the unique experiences of marginalized groups. As a related, but standalone concept to Critical Legal Studies, CRT has been used in various disciplines, from education to political science and social work, to examine the relationship between race, racism, and power (Taylor, 2009). Despite its wide application, there are some main tenets to CRT, five of which directly relate to my theoretical assumptions about race and use of self.

The first tenet of CRT is that racism is a well-established part of society. Given its deep entrenchment within society - in customs, experiences, and structures - racism should be viewed as central to human experience (Crenshaw et. al, 1995; Solórzano \& Bernai, 2001). At the same time, racism's ordinary presence makes it invisible to those who hold racial privilege, and makes it difficult to correct (Constance-Huggins, 2012; Taylor, 2009; Yosso et. al, 2009). Ortiz \& Jani (2010) go as far as to say that CRT recognizes race as a relational concept whose main goal is to stratify and separate. Through internalization of these racial categories, individuals evaluate themselves and 
others. Therefore, race becomes one way society organizes itself, and one way individuals organize self and other.

CRT rejects liberalism as a political doctrine because it upholds unrealistic ideas of meritocracy, equal opportunity, and color-blindness (Razack \& Jeffrey, 2002). Through a critique of liberalism, the second tenent of CRT, critical race theorists reject dominant narratives that assume equal opportunity exists for all peoples. Instead, they hold that race's ordinary presence in society makes it challenging for racialized peoples to gain access and power; they are often unable to completely step outside the racial categorizations and bias imposed upon them.

In addition, the critique of liberalism acknowledges that power has often been granted to dominant groups (Gotanda, 1995; Yosso et. al, 2009). For instance, since the early years of the United States, cismen of European descent have been able to serve on juries, thus having power to sentence Black and Brown persons under the power of the law. CRT recognizes the institutionalized power granted to Whites and the struggles BIPOC communities face to obtain civil rights. Thus, CRT holds that liberalism ignores the historically slow process of extending rights to BIPOC communities (Yosso et. al, 2009). Liberalist conversations of meritocracy, equal opportunity, and color-blindness only benefit those who already hold power (Gotanda, 1995; Kolivoski et. al, 2014).

Third, CRT holds that race and races are socially constructed by dominant groups to protect their interests (Bell, 1979; Haney-Lopez, 1994; Taylor, 2009). Through the creation of racial categories, dominant groups have been able to decide which groups have access to rights and which groups do not. As a system, race functions to categorize 
people based on their physical characteristics, though there are no biological correlations to these racial categorizations (Constance-Huggins, 2012).

The effects of race as a social construct can be seen in social work's early history. During the progressive era, the mainstream settlement movement focused on social and welfare supports to immigrants and migrants (Berman-Rossi \& Miller, 1994). People like Jane Addams led the charge. However, Blacks were served in separate agencies specifically racially oriented ones - at separate times (Berman-Rossi \& Miller, 1994; Hounmenou, 2012). Even worse, when Black families moved to neighborhoods with settlement houses their presence meant the neighborhood was in decline (Hounmenou, 2012); therefore, settlement houses were relocated or abandoned. To be put bluntly, rather than serve Blacks alongside European immigrants, settlement programs simply migrated to a different part of town. The fact that such explicit exclusion of Black peoples would be considered horrific today, highlights race as a socially determined, yet powerfully constructed tool; a tool which potentially affects the practice experience of BIPOC social workers.

The fourth tenet of CRT relevant for this dissertation is anti-essentialism. One of the many downsides to racial categorization is that it ignores other ways individuals could be marginalized. Anti-essentialism holds that an intersectional approach to identity is necessary to avoid further replication of oppressive structures (Crenshaw et. al, 1995; Hylton, 2012). Since everyone has intersectional identities that may overlap and/or conflict (Taylor, 2009), focusing on one identity replicates the idea that a person can be contained in one category. Thus, while CRT centers race, it also recognizes the effects of 
other kinds of oppression - for example, immigration status, gender, sexual orientation on human life (Constance-Huggins, 2010; Ortiz \& Jani, 2010). This intersectional approach recognizes that one's experience is dependent on a myriad of factors. No one is only one thing.

Finally, Critical Race theorists center the viewpoints of racialized peoples in order to rebuild our flawed and racialized society (Calmore, 1995) Based on their varying histories, and personal experience with race and racism, racial minority groups have unique insights (Bell, 1995; Ortiz \& Jani, 2010). Barnes (1990) calls this insight racial distinctiveness. Thus, in order to contrast master narratives, the final tenet of CRT encourages BIPOC writers to share counternarratives (Constance-Huggins, 2012; Taylor, 2009). Through sharing their stories, racialized peoples can teach about racial oppression and translate their struggles into social action (Yosso et. al, 2009; Ortiz \& Jani, 2010).

Advancing marginalized voices through counternarratives is a key principle of $\mathrm{CRT}$ in that it asks racialized peoples to reclaim their stories and experiences for social change to occur. Sharing counternarratives is one specific way critical race theorists enact social justice. It not only allows them to collect alternative histories of events, based on non-dominant experiences, but to use storytelling to directly challenge liberalist notions of meritocracy, color-blindness, and equal opportunity.

\section{Critical Race Theory and Use of Self}

When combined, all five tenets of CRT connect to my assumptions around race and use of self. As noted by Haney-Lopez (1994), race is a relational concept because races exist in comparison to each other; for instance, the construct of Whiteness relies 
upon the construct of Blackness in order to exist. Following CRT's first tenet, my first assumption is that if race organizes society, then racial categorizations (and our internalization of them) also impact interpersonal relations. It affects how therapists and clients interact.Therefore, society's racial categorizations are not just abstract. Instead, these racial categories affect the ways in which social workers, particularly BIPOC social workers, engage with use of self to form relationships with clients and affect change. In sum, if racism organizes society, then it also organizes the contexts in which social workers practice.

Secondly, in the introduction I described that those in dominant positions get to assess what should be considered knowledge, and are viewed as knowledge generators by society-at-large (Collins, 2000; Janack, 1997). This same knowledge is then granted power socially and in the academy, without acknowledgement of minority experiences. As a result, concepts like use of self are understood through colorblind narratives which assume that dominant narratives are the only narratives. Hence, the second tenet highlights my second assumption - as we do not live in a colorblind society with equal opportunity for all, interpersonal relations and use of self are neither color-blind, nor equal across racial groups.

My third assumption, race as a social construction, dovetails with my first - since race is socially constructed, and is an ordinary part of society, race may also affect intraand interracial relations. Therefore, the social construction of race could impact the practice experience of BIPOC social workers, both with members of their own communities, and members of dominant groups. Through this dissertation, I gain a 
snapshot of race and practice in the 21 st century. Since race and its effects continue to shift over time, it is useful to note how current understandings of race affect social work practice today. Not only will this benefit current social work practitioners, but it may aid future BIPOC social workers as they compare today's socio-cultural practice realities with their own.

Next, while this dissertation centers race and use of self, my fourth assumption is still worth mentioning: race may be one of many components of use of self missing from the scholarly literature. Other identities such as religion, age, gender, class, and more, may all intersect and overlap when BIPOC social workers use of self. These identities may overlap in both explicit and implicit ways. Therefore, during data analysis, I considered how salient identities, outside of race, impact participant use of self. These other salient identities may have changed how participants understand their use of self. In spite of these considerations, the present study still centers race which breaks from CRT's anti-essentialist orientation. Therefore, one limitation of the present study is its primary focus on race, and not additional factors that may contribute to how racialized peoples use self.

While this is the final tenet of CRT to be reviewed, advancing marginalized voices is a guiding light for this research study. My final assumption is that as a field, social work can do more to uplift the subjugated knowledges of BIPOC social workers. In addition, social workers are meant to uphold principles of social justice. That counternarratives exist, should be enough to indicate something to social work: solo narratives tend to favor those in power. In its stead, a consideration of both dominant and 
counternarratives will offer social workers a deeper understanding of social structures. The same social structures the profession wants to change. Therefore, social workers can contribute to social change by paying attention to counternarratives. Through counternarratives, social work can better understand that race may impact use of self; as a result, race should be researched as a component of use of self.

To conclude, Critical Race Theory aligns with the assumptions undergirding this study: first, that race organizes society, and therefore it organizes the contexts in which social workers practice; second, since we do not live in a colorblind society with equal opportunity for all, interpersonal relations and use of self are neither color-blind nor equal across racial groups; third, the social construction of race could impact the practice experience of BIPOC social workers; and finally, solo narratives favor those in power so it is important that social workers contribute to social change by paying attention to counternarratives.

A number of social work scholars are applying CRT principles to the profession's mission and values (see Kolivoski et. al, 2014), approach to multicultural education and diversity courses (see Abrams \& Moio, 2009; Constance-Huggins, 2012; Ortiz \& Jani, 2010) and pedagogy (see Razack \& Jeffrey, 2002). They have made it clear that the principles of CRT align with the social work profession's orientation toward social justice and advocacy. In addition, the authors indicate CRT's utility in all areas of social work practice. The next section explores the principles of Social Identity Theory, which highlight additional assumptions around race and use of self. While Critical Race Theory provides a macro view of society, Social Identity Theory takes a micro look at social life. 


\section{Social Identity Theory}

Social Identity Theory (SIT) is considered a preeminent theory within social psychology (Brown, 2000), and is well-respected worldwide for redefinining intergroup relations (Hornsey, 2008). SIT was developed by social psychologist Henri Tajfel and his graduate student John Turner after a series of studies concerned with a deeper understanding of prejudice and conflict; particularly after the holocaust and WWII (Jenkins, 2008). Tajfel and Turner's research aimed to "establish minimal conditions in which an individual will, in his behaviour, distinguish between an ingroup and an outgroup" (Tajfel, 1974, p. 67). They found, through numerous social experiments, that participants favored those in their social experimental group, and attempted to achieve maximum difference between their group and the other (Tajfel, 1974).

At its core, SIT is about inter-and-intra group relations: how people categorize their self-defined social group against other groups (Brown, 2000; Stets \& Burke, 2000). Arguably the most central aspect of social identity theory relates to social categorization. Social categorization posits that humans organize their social environment into personally meaningful categories or groupings (Tajfel, 1974). Groups are loosely defined as individuals who share an identity - for example a shared gender identity or shared profession. The consequence of these social categorizations is an accentuation of ingroup similarities alongside an accentuation of out-group differences (Stets \& Burke, 2000). Within social categorization, it is important to note that groups do not exist in isolation, but interact with each other. Thus when one category exists, it inherently 
creates another (Tajfel, 1974). For example, the gender binary forces the idea that the category male should only exist next to the category female.

It is important to note that in SIT, any characteristic can be used as a categorical tool (Cox \& Gallois, 1996) - from shared heritage to one's neighborhood. Because social identity theory holds that the self is reflexive - meaning it can position itself relative to social categories or classifications - individuals can elect (or not) to move through social categories (Stets \& Burke, 2000). Hence, a person's social identity is not static, but may shift over time (Tajfel, 1974). For instance, at one point in time a social worker may be a student, yet at another time a professor.

Most important to self in social identity though, is that social identity facilitates social categorization. By placing ourselves into groups, humans automatically create an 'in-group' and an 'outgroup' where the 'in-group' belongs, and the 'out-group' does not. Furthermore, social identity theorists note that individuals evaluate a group positively when they become a group member (Stets \& Burke, 2000). The positive evaluation results in increased self-esteem, which validates one's self-understanding. In essence, social identity theory holds that through upholding differences between groups, differences that may or may not exist, individuals gain a stronger understanding of where they fit into society (Tajfel, 1974).

\section{Race and Social Identity}

Social identity theory was "the first social psychology theory to recognize that different groups occupy different levels of a hierarchy of status and power, and that intergroup behaviour is driven by people's ability to be critical of, and to see alternatives 
to, the status quo" (Hornsey, 2008, p. 207). Therefore, racial prejudice and stereotypes are actually about individual desires to align themselves with social groups that appear superior in order to enhance self-esteem. Consequently, members of one's racial in-group for example, are evaluated positively whereas outgroups, or those of other racial identities, are considered different and therefore are evaluated negatively (Nesdale, 1999). Hence, self-categorization allows individuals to develop social identities and these social comparisons facilitate their positive self-esteem (Cox \& Gallois, 1996).

Because social categorization is motivated by self-esteem, one's social categorization depends on an assessment of which identity category is most salient to the specific context (Jenkins, 2008). In social identity theory, a salient identity is an activated identity (Stets \& Burke, 2000). Meaning, a person's context dictates which identity would be considered salient at what time. In this way, context becomes key to understanding social categorizations, as context shapes who we consider in-group and who we consider outgroup. It allows people to "self-categorise themselves differently according to the contexts in which they find themselves and the contingencies with which they are faced" (Jenkins, 2008, p. 112)

Noteably, individuals with multiply marginalized identities (ex: queer, Latinx, disabled) might find it harder to develop self-esteem through group membership because of negative reactions to their other identity categories. For instance, they may feel included in queer spaces, but excluded in Latinx-only spaces.

About race, Tajfel (1974) states: "Whatever its other uses may be, the notion of "race" has become in its general social usage a shorthand expression which helps to 
create, reflect, enhance and perpetuate the perceived differences in "worth" between human groups or individuals" (p. 75). He understood that race, though arbitrary, became a categorical tool that allowed one group to claim dominance over others through evaluating their group positively, and others negatively. Given this dissertion's focus, two components of SIT directly relate to my argument about race and use of self: social categorization and social context.

\section{Social Identity Theory and Use of Self}

Social categorization and context illustrate my final two assumptions about race and use of self. Since humans cognitively categorize themselves and others into groups, and race is certainly a social grouping (per Critical Race Theory), then it is possible for racial differentiation (out-group), and racial similarities (in-group) to impact a social worker's use of self. It may also affect how they are able to use self to affect client outcomes - a client's identity as well as perception of what racial group their social worker belongs in may change the ways in which a client and social worker engage each other.

Therefore, my first assumption with SIT and use of self is that racial categorizations may affect the ways in which BIPOC social workers use self in their practice, both intra- and inter-racially. For instance, a social worker may develop stronger relationships within their racial group, but struggle to engage cross-racially, or vice versa. Not always because of bias, but because it is a group separate from their own. Hence, race could impact use of self. 
Secondly, context could influence when race is activated as a social identity within social work practice. For instance, when working within a culturally specific agency with members of their own racial groups, the ways a BIPOC social worker uses self could look different than if they worked at an agency with mostly White clients. Thus, a social worker of color in a culturally-specific agency may activate race in that context, and another social identity (for example, religion) in an alternative context.

Social Identity Theory offers a view into social relationships, namely how social groups relate to each other. As social workers are humans, who belong to social groups, it is worth exploring how these groupings, especially around race, factor into our practice realities. I believe that racial categorizations (in-group and out-group) can affect how the 'self' of a social worker is perceived (insider or outsider), which then impacts their ability to use that self to facilitate client change. In addition, context could influence when race is activated as a social identity - the in-group/out-group context, or even the context of the space. In this way, use of self is dependent on how both clinician and client assess which identities are most salient to their particular interaction.

\section{Chapter Summary}

Before concluding this chapter, it is useful to briefly note the similarities and differences between CRT and SIT. The primary area of divergence is that CRT provides a macro understanding of social relations whereas SIT offers a more micro view. Though not inherently problematic, it means there may be additional mezzo-level factors which are just as influential to how social workers of color use self; these include agency structure, and the communities in which they practice. 
At the same time, CRT and SIT converge in very meaningful ways. First, both CRT and SIT acknowledge that race is one of the ways society organizes individuals, and one of the ways individuals organize themselves. Second, both theories are intersectional; they recognize that race is one of many categories which organize society. Third, both CRT and SIT recognize that social categories are defined by the societal context. Therefore, categories like race are socially constructed, and therefore can change over time. Lastly, both CRT and SIT aim to expose power hierarchies within social groupings; hierarchies which influence individual experience, and potentially influence social worker use of self. These theories, CRT and SIT, indicate race as a grouping which structures society, and factors into micro-level social interaction. As a result, they validate my assumption that race may impact use of self and thus, race should be researched as a component of use of self.

This chapter reviewed the literature and theories that inform the present study including: the background and origins of use of self, how it has been defined and applied in the literature, and an overview of Critical Race Theory and Social Identity Theory as it relates to the assumptions guiding this study. The next chapter will delve into my ontological and epistemological orientation, as well as methodological considerations for the study. 


\section{CHAPTER THREE: METHODOLOGY}

Throughout this dissertation I aim to expand present understandings of use of self by engaging the subjugated knowledges of BIPOC social workers. Without considering the influence of race on use of self, the practice field will continue to perpetuate the privilege given to dominant culture discourses within social work knowledge production. In this research study I utilized an Interpretive Description methodology, which holds that researchers must "...credibly conclude that there is relevant knowledge to which actors within the field have experiential access that has not yet been sufficiently documented, described, or interpreted to make that level of knowledge useful in some manner to a discipline's activity or project (Thorne, 2008, p. 64). Since this is a practicedriven dissertation, I adopted a practice-focused methodology and qualitative design.

Merrick (1999) states that in order for qualitative researchers to increase reliability and validity they must speak to trustworthiness, reflexivity, and representation. Trustworthiness includes factors such as explicit description of biases and deep engagement with data; reflexivity relates to clarity around the experimental process; and lastly, representation refers to the ways in which the findings are coded and presented. This chapter engages trustworthiness, reflexivity, and representation through discussions of the study's epistemology, methodology, study design, and ethical considerations. I also engage with reflexivity throughout by elucidating my positionalities as it relates to this research. 


\section{Ontology \& Epistemology}

Critical theory provides a framework for understanding how the social order runs, what place and role each of us has within it, the effect the system has on us, and what we can do to change it. It is a combination of the macro analysis of human behavior in the social environment, blended with the micro analysis of transference and countertransference, distilled together to determine what course of action we need to take to change injustices of the current system.

- Salas and Segal, 2010, p. 92

As a critical theorist, I do not believe in an objective truth. Instead, I believe that as researchers, our life experiences affect the things we study, and the ways in which we study them. For instance, my experience as a social worker informed my interest in the study, and the way I approach my study design and data analysis process. I align myself with a critical ontology which recognizes a historically based reality that is tied to social and political processes around power and privilege (Howell, 2013; Williams, 2006). From a critical viewpoint culture cannot be understood without understanding a person's history; a history that is rooted in oppressive incidences which hinder cultural expression (Williams, 2006). Under critical ontology, factors like race, influence one's reality. My critical ontology also connects to a critical epistemology. Critical epistemologies aim to change the status quo by examining power, privilege and oppression (Crotty, 1998). 
These epistemologies are based on a critique of the positivist notion that one can be an objective knower of the world (Morrow, 1994). In place of positivist assumptions, critical epistemologies claim that the search for knowledge is not just for knowledge's sake but to be "emancipatory knowledge, knowledge in the context of action and the search for freedom" (Crotty, 1998, p. 159). For the critical theorist, research must be entered into with "assumptions on the table, so no one is confused concerning the epistemological and political baggage they bring with them to the research site (Kincheloe \& Steinberg, 2005, p. 306).

Though there are several orientations that fall under critical epistemologies - such as feminist, indigenous, and critical race - the present study is deeply rooted in critical epistemologies more broadly. Marx is cited as a key figure in the development of critical theory due to his activist view that philosophy should not just interpret the social landscape, but also change it. The Frankfurt School later developed as a hub for leading intellectuals, like Theodor Adorno and Max Horkheimer, who believed that knowledge should be used for social change (Crotty, 1998; Salas \& Segal, 2010).

Within critical epistemologies, there is a belief that knowledge should be developed to counter privilege and oppression (Anastas, 2014). Schwandt (as cited in Stage, 2007) note five themes of critical epistemologies. First, theory and practice are integrated with each other; therefore, this research aims to connect the theoretical understandings of use of self with the practice realities of BIPOC social workers. The second theme is that power and oppression are part of social life, therefore, research must 
be anti-oppressive, political, and ethical. As a result, this dissertation is anti-oppressive and political in its focus on shifting dominant narratives through counternarratives.

Next, in critical epistemologies, researchers must be aware of their personal privilege and how it affects their interactions with others; they should also attempt to transform dominant narratives. As a doctoral student I hold immense educational privilege. In addition, as a practicing social worker, my professional obligations placed me in powerful positions in certain spaces (ex: gatekeeping of agency resources) yet powerless in others (ex: within organizational structure). Therefore, it was important that throughout the study I considered my own privileges as it relates to this work, as well as how the privileges of researchers before me influenced the ways we think about use of self -- namely, that previous researchers either assumed practitioners have a dominant racial identity and/or that identity categories like race, do not affect use of self in practice.

A final component of critical epistemologies is that they should engage equal participation between researchers and subjects. Since the methodology guiding this research - Interpretive Description - does not center equal participation, I instead conducted a preliminary analysis of initial interviews, and shared those initial findings with interviewees so they could reflect on how their experience connected to what their peers described (Thorne, 2008). In this way, participants at the very least informed the research during the data collection and analytic phases of the study. The next section connects the study more explicitly to an Interpretive Description methodology. 


\section{Interpretive Description}

Research drawing on these ideas involves cultivating the skill of appreciating experience from the perspective of others, while simultaneously accounting for the cultural and social forces that may have shaped that perspective Thorne, 2008, p. 49

Interpretive Description (ID) was developed by Thorne, Reimer Kirkham, and MacDonald-Emes (1997) as a means to reject traditional methodologies that centered theory, and not practice (Brewer et. al, 2014). Its goal was to create a knowledge base whose findings could be applied to practice, and was relevant for the discipline. In this way, ID is a form of "disciplinary knowledge development" (Thorne, 2008, p. 67) that requires scholars have sufficient knowledge of the field of study, and use that expertise as a basis to explore research questions to advance the discipline. In fact, having an expertise in the field of practice is viewed as an important starting point to rigorously explore an issue (Hunt, 2009). Thorne (2008) elaborates that this is because ID challenges researchers to see patterns and themes within a clinical issue, and then use that understanding to explore alternatives to how a phenomenon is presently understood. If a researcher is not steeped in the area of practice, they do not have a solid foundation to begin applied research. For this reason, I believe my practice insights (see introduction) are valuable for this study, and offer a strong foundation for the present research.

Because interpretive description is about returning knowledge to the practice realm, studies should involve key informants. These key informants are professionals in 
the field who are able to offer insight into what is happening, and inform the researcher. Thorne (2008) notes, "I find that including a mechanism for locating and tapping the wisdom of those whose professional commitment embeds them in the field every day is a valuable design element" (Thorne, 2008, p. 85). Therefore, in order to answer the research questions, I interviewed practicing social workers who served (or could serve) as field instructors to social work students. As I mentioned in the introduction, I believe that field instructors provide specific insight on use of self because they are connected to both social work education and the practice field, and as a result of their supervisory role with students, are constantly thinking and observing the practice experience. These social workers are key informants.

It should be noted that the main critique of ID is its relative newness (Hunt, 2009). Therefore, ID research studies must show rigor in the research design and implementation. Despite its newness, the literature includes texts on its analytical objective and processes (Thorne et. al, 2004), examples of successful ID research studies (ex: Clark et. al, 2011; Kalengayi, et al., 2012; Murphy et al., 2016; Olsen et al., 2013), and scholarship on how each stage of the research design should proceed (Thorne, 2008), which we will explore in the next section.

\section{Research Design}

Thorne (2008) notes there are some common features of interpretive design studies. These studies are: conducted in a naturalistic setting that respects the ethics of participants; attend to the value of subjective and experiential knowledge for practice insights; focus on commonalities in the human experience as well as individual variance; 
attend to the time and context of human expression; hold that human experience is socially constructed; there is not a singular reality, but multiple constructed realities that sometimes contradict; and hold that the 'knower' and 'known' are inseparable and influence the research product. These foundational underpinnings are weaved throughout this research study, and helped answer these research questions:

- What are the components of use of self, as defined by BIPOC social workers?

- How have they used self in their practice and to what effect?

- How do issues of race and racism affect their perceptions of using self in practice contexts?

\section{Context}

Since ID studies must attend to the time and context of human expression (Thorne, 2008), it is important to understand the context of this present study. The study was partially embedded within an IRB-approved study (PI: Dr. gita mehrotra), which explored the experiences of social workers of color who serve as field instructors. The larger research study was funded to include three focus groups and twelve individual interviews. Through my collaboration with Dr. mehrotra, I gained access to BIPOC social workers (within a historically White city and state), and was able to insert my research questions into the interview guide.

Because use of self is a relational concept, I initially believed I could answer my research question through focus groups. I felt that because focus groups allow participants to respond to the researcher and each other (Hesse-Biber, 2017), focus 
groups would facilitate a richer understanding of the interpersonal dimensions of use of self. In addition, I understood that focus groups could facilitate culturally sensitive research because in its homogeneity, focus group research offers researchers an opening into how vulnerable populations engage in the social world (Hughes \& DuMont, 1993). However, after the first focus group, it was clear that I needed to revise my questions because participants did not always understand what I was asking; participants frequently answered my question by asking me to clarify what I meant. Furthermore, if one person answered my question, others sometimes responded similarly, which limited nuance within the data that was collected.

As a result of piloting my questions in a focus group, I learned that I needed to ask about use of self in a more concrete way. In addition, I realized that while use of self was a relational concept, in order to understand BIPOC experiences, I needed the opportunity to ask personalized follow up questions -- an option that was not available during focus groups. Therefore, the focus groups served as a pilot for my research questions, and informed my decision to conduct semi-structured individual interviews. Methods

After asking and revising my questions across three focus groups, it was clear that individual semi-structured interviews were the best way to understand how social workers of color perceived and experienced use of self, and how race factored into their use of self. This decision was also informed by Rubin and Rubin's (2005) guide to determining the suitability of qualitative interviewing to the research question at hand. The authors ask researchers to consider: 
Are you looking for nuance and subtlety? Does answering the research question require you to trace how present situations resulted from prior events? Is an entirely fresh view required? Are you trying to explain the unexpected? Does puzzling out the research question necessitate layers of discovery in which initial questions are asked to discover alternatives that are then explored in turn? (p. 47-48). Upon answering Rubin and Rubin's (2005) prompts, semi-structured interviewing made the most sense for this study. First, interviews offered a path for a nuanced understanding of race within the concept of use of self. Second, while this research does not trace how the past affects the present, individual interviews opened a path to trace how participants used self, and how they saw that self as connected to either their race or that of their clients. In other words, instead of tracing history, this study allowed me to trace participant perceptions. Third, based on a review of the literature (as discussed in chapter 2), social work needs an expanded conceptualization of use of self. Therefore, interviews offered a chance to expand the concept to consider race. Fourth, interviews facilitated a deeper dive into the unexpected (Rubin \& Rubin, 2005). Interpretive Description posits that human experience is socially constructed (Thorne, 2008); therefore, interviews are a method that allowed for a deeper dive into participants' socially constructed realities as it relates to race and use of self. Lastly, given ID's understanding that multiple realities exist (Thorne, 2008), semi-structured 
interviewing created an opportunity for follow-up questions which then opened up alternative understandings and multiple perspectives on use of self. Participants \& Setting

Data saturation is not important to an interpretive description methodology (Thorne, 2008). Instead, researchers must focus on "the point at which the practical question driving the study has been reasonably answered" (Oliver, 2012, p. 413). My research questions were reasonably answered after conducting interviews with 27 BIPOC social workers who held varying racial identities, and worked in diverse practice settings. Participants were extremely experienced with most having between 5 and 19 years experience, alongside a commitment to issues of racial equity both personally and professionally. Participant demographics are detailed in Table 1.

Similar to the pilot study, field instructors were recruited with support from faculty and the field education team at Portland State University and University of Portland. They provided an initial list of social workers who met the criteria for the study: service as a field instructor (or ability to serve) for students, and identification as a racialized person (namely African-American/Other Black, Asian/Asian-American, South Asian, West Asian/Arab/Middle Eastern, Pacific Islander, First Nations/Alaskan Native/Native American/Indigenous, Chican@/Latinx or Multiracial/Mixed Race). After a recruitment list was created, I contacted each field instructor to inform them of the project, and to learn if they were interested in participating. 
Table 1: Participant Demographics

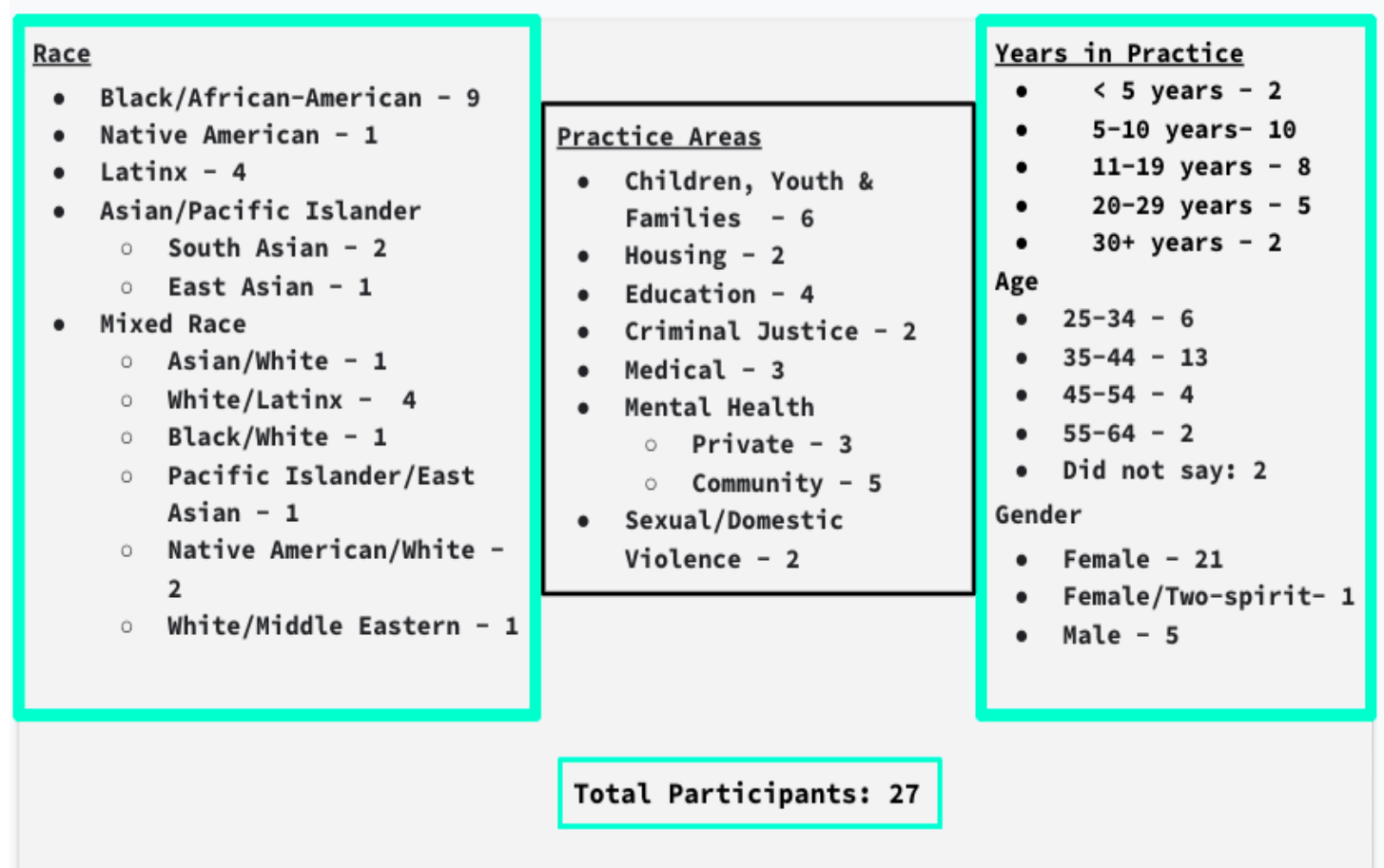

One of the foundational underpinnings of interpretive description is that research is done in a naturalistic setting that caters to the ethics and needs of participants. In order to cater to the ethics and needs of interviewees, I scheduled individual interviews during a time most convenient to participants. This aided in recruitment, and upheld ID's foundational values. Prior to the start of the interview, participants completed a demographic form which asked their race, gender, age, ability status, agency setting, and areas of practice. I reviewed the informed consent with every interviewee, and obtained their permission to audio record the interview. Participants received a $\$ 20$ gift card as an honorarium for their time. After all the interviews were completed, recordings were sent to a transcriptionist. To maintain confidentiality, only myself and Dr. mehrotra had 
access to recordings, forms and transcripts. Furthermore, identifying information was stored separately from transcripts.

For this dissertation, I asked participants these questions:

1) What drew you to the social work profession?

2) What keeps you in the profession?

3) Use of self is defined as the social worker's instrument, and is when a worker pulls from their personal characteristics to build relationships with clients and facilitate client change. Please think about a time where you had a particularly meaningful interaction with a client. What parts of who you are did you use to help facilitate change? Take your time.

a) Why did you use those parts of yourself?

b) What benefits have you seen for your practice and for the clients you work with when you use those parts of yourself? (Provide examples)

c) What disadvantages (if any) have you experienced when you use those parts of yourself? (Provide examples)

d) What enables you to use self?

e) How does being in Portland affect your use of self as a BIPOC person? How does it compare to other places you have lived? (Provide examples)

f) How does the culture at your agency affect your use of self?

4) What effect does race (yours or your client's) have on your ability to use parts of who you are to facilitate client change? (Provide examples) 
a) What has it been like to work with members of your own community and/or people of color compared with Whites? (Provide examples)

b) How does race affect the way you practice social work?

5) Is there anything else you wish to share?

After each query, I asked personalized follow-up questions to gain more data on participant perceptions. Within ID it is vital that the researcher asks broad questions of the data to understand what is being said overall (Hunt, 2009). Foundationally, researchers should also focus on commonalities in the human experience as well as individual variance. Therefore, reflexive memoing is crucial. After every interview I noted key points participants made, how my questions were received, initial impressions, and made connections across interviews. Those notes were particularly useful during the data analysis phase of the study.

\section{Data Analysis}

In considering an analytic approach, it was important to consider which orientation would best answer the research question, stay true to my values around subjugated knowledges, and align with an ID methodology. Given the exploratory nature of this research, thematic analysis was the best analytic option; it offered a way for me to remain close to the data while still exploring the landscape of BIPOC practice experiences.

In thematic analysis, themes arise from concepts in the data, and through iteration, offer a nuanced view of an issue (Rubin \& Rubin, 2005). Specifically, themes allow researchers to understand a topic by examining its properties and dimensions (Corbin \& 
Strauss, 2008). Furthermore, the purpose of interpretive description is to offer a thematic summary of an issue, which allows a researcher to organize a larger phenomenon into organized aspects (Thorne, 2008). Given my knowledge of the literature on use of self, I believed that a deductive and inductive approach to thematic analysis was necessary. The bottom-up inductive approach meant I could deeply focus on what participants were saying, and the top-down deductive approach meant I could connect participant experiences with CRT and SIT, the literature on use of self, and the social realities of race. The flexibility of thematic analysis (Braun \& Clark, 2012) made it a perfect fit for the present study.

Braun and Clark (2012) state that in order to conduct good quality thematic analysis, researchers must be clear about their decision-making process, provide rationale for choices made, and consistently apply their choices during analysis. I closely followed the authors' six phase approach to thematic analysis, and used Atlas.ti software to help organize codes, themes, memos and findings. Each phase of data analysis is discussed in detail below.

\section{Phase 1: Get Familiar with Data}

In this phase, I read and re-read transcripts. I also listened to the audio once to ensure the transcript matched the audio then a second time to ensure I understood the properties and dimensions of what participants said (Braun \& Clark, 2012; Corbin \& Strauss, 2008). Since there is no member checking within interpretive description, I instead conducted a preliminary analysis of early interviews, and gave later interviewees a chance to reflect on how their experience married with a synthesis of the earlier group's 
responses (Thorne, 2008). In this way, participants had a chance to challenge my conceptualizations with their own insights and allowed me to "come away with confidence that conceptualizations are, indeed, grounded in data and representative of shared realities rather than an artifact of design or instrument (researcher) error" (Thorne et. al, 1996, p. 175).

ID asks that researchers remain reflexive throughout the entire research process because the 'knower' and 'known' are inseparable and influence the research product (Thorne, 2008). Therefore, I maintained post-interview memos to recall my experience. These memos included key points participants made, how my questions were received, notes about my own use of self, initial impressions and connections across interviews. Through continual emergence in the data, engaging participants in preliminary findings, and memoing, I stayed familiar with the data.

\section{Phase 2: Generate Initial Codes}

Codes provide labels to answer the research question (Braun \& Clark, 2012). Thorne (2008) argues against predetermined codes that are not linked to the data since these initial codes are hard to let go of, and limit the researcher's ability to reconceptualize, synthesize and theorize (Oliver, 2012). Instead, the ID initial coding process involves going through transcripts and asking broad questions, like "What is going on here?" and "What am I learning about this?” (Hunt, 2009, p. 1286). This allows the researcher to move away from initial theorizing towards a deeper understanding and interpretation of the data (Hunt, 2009). 
Therefore, the second phase involved detailed coding of both semantic and latent themes, where I asked the data broad questions, such as the ones listed above. I then developed in-vivo codes as much as possible, which used the same language/expressions voiced by participants. Because this research centers subjugated knowledges, I believed in-vivo coding was necessary for a number of reasons. First, I hold that sharing nondominant perspectives requires researchers to use the language/constructs utilized by those groups in order to remain true to their statements. Second, researchers often translate participant experiences to specific audiences (Corbin \& Strauss, 2008), and so it was important to me to use participant language as much as possible. Lastly, ID understands that participant realities are socially constructed. Therefore, in order for me to highlight subjugated knowledges, I needed to use text which stayed true to participant realities.

\section{Phase 3: Search for Themes}

In the third phase of data analysis, I began actively searching for themes (based on the initial codes) to note patterns in the data (Braun \& Clark, 2012). This process was particularly challenging because I wanted to be inductive and deductive, explore both latent and semantic themes, and also remain true to the methodology and research question. In addition, since the questions I posed to participants easily align with my research questions, it can be easy to default into simply relating each theme to each question. However, a richer analysis required exploring themes across questions.

In fact, researchers who engage with interpretive descriptive methodology do not simply look at the data from a surface level. Instead, they try to create a "coherent 
conceptual descrip- tion that taps thematic patterns and commonalities believed to characterize the phenomenon that is being studied and also account for the inevitable individual variations within them" (Thorne et al., 2004, p. 3). Therefore, my search for themes involved asking myself how the themes were described across interviews, as well as within participant stories.

\section{Phase 4: Review Potential Themes}

The fourth phase involved reviewing the themes in relation to all the codes, and the entire data set which provided a kind of quality check (Braun \& Clark, 2012). Per Braun \& Clark's guidelines, I asked myself the following questions: "Is this a theme (it could just be a code)? If it is a theme, what is the quality of this theme, does it tell me something useful about the data set and my research question? What are the boundaries

of this theme (what does it include and exclude)? Are there enough (meaningful) data to support this theme (is the theme thin or thick)? Are the data too diverse and wide ranging (does the theme lack coherence)?” (p. 66).

After answering each question, I worked to ensure there was not a mismatch between the theme and the data. In other words, I continually returned to the original transcripts to check that themes were actually reflected in the data. Furthermore, I carefully collapsed, added, and discarded themes as necessary to further ensure a meaningful connection between themes and the data.

\section{Phase 5: Define and Name Themes}

Within interpretive description, themes ground the analytic work because they highlight individual and collective conclusions which contribute to a general pattern 
(Thorne, 2008). Therefore, in the fifth phase of thematic analysis, I defined each theme to note what makes it unique and specific to the research question at hand (Braun \& Clark, 2012). In addition, I considered how best to tell the story of the data. That meant considering which themes best answered the research questions, and which excerpts should be included to help define the theme.

It is important to note that defining and naming themes allows researchers to view the essence of a phenomena "to understand what we are likely to encounter in future clinical practice and to have some meaningful sensitivity around it (Thorne, 2008, p. 79). Therefore, this fifth phase was particularly important; it is where theory met practice, and patterns in the data offered insights with potential to enhance clinical practice.

\section{Phase 6: Produce a Report of Findings}

I explore the content of my findings in detail in the next chapter but in this final phase of data analysis, I "provide a compelling story about [my] data based on [my] analysis" (Braun \& Clark, 2012, p. 69). In an interpretive descriptive framework, findings are organized in such a way that it influences how experts in the field engage in the work (Hunt, 2009). This can be done in two ways - findings can be organized following an overarching claim, or can use a sequenced framework which allows a story to develop (Thorne, 2008).

Given the nature of this study, I believed it was best to organize findings based on overarching claims that arose from the data. Therefore, findings were organized in a way that let me present themes as they relate to each other. In this way I can illustrate "how elements within the larger phenomenon can be ordered and organized to reveal aspects 
that would have been obscured through any other presentation framework" (Thorne, 2008, p. 173). Thus, the end product is an enlightened conceptualization, without throwing out existing concepts or creating new ones (Thorne, 2008).

Trustworthiness and Rigor. In order to maintain trustworthiness and rigor throughout the research study (Morrow, 2005), I wrote memos after each interview where I provided a brief summary of the conversation, noted initial impressions and explored participant ideas around race and use of self. I also engaged memoing throughout the analytical process to explore relationships between concepts. Since member checking is inconsistent with an ID methodology, I instead conducted a preliminary analysis of early interviews and gave later participants an opportunity to reflect on a synthesis of the previous group's experiences. This was important because it gave participants a chance to offer insights into initial codes developed; codes which were based on BIPOC experiences and not the general literature on use of self. Lastly, I used peer debrief during analysis as a way to remain close to the data and explore additional perspectives. I spoke with two members of my dissertation committee with practice experience about initial thoughts and themes. I found their insights, questions, and feedback added even more nuance to my analysis.

\section{Reflexivity and Ethical Considerations}

Interpretive description, like all qualitative approaches, explicitly recognizes and capitalizes on the researcher as instrument...there are several linked elements to this theoretical forestructure: a) locating your theoretical 
allegiances on entering the study, locating yourself within a

discipline, and locating your personal relationship to the ideas you hold (Thorne, 2008, p. 64)

I conclude this chapter with a discussion of my positionalities as it relates to this work, and ethical considerations during research. There were certainly a number of considerations around reflexivity, and I believe they all contributed to the ways I understood and analyzed how BIPOC social workers used self in practice. First, as a social work practitioner and Black woman, I automatically entered interviews with some understanding of race's impact on practice realities. These understandings may have led me to assume I understood participant realities, when in fact they might have differed from my own. Therefore, during interviews I continually asked clarifying questions, in order to stay close to participant experiences. These questions were particularly important for credibility during analysis because clarifying questions provided more data from participants' own words, and allowed me to attend to how questions were being received and/or understood.

Second, it is possible that due to being a fellow racialized person, the information participants shared with me was informed by how my 'self' presented during the interview. I did not believe this was problematic, especially since I hold that the 'knower' and 'known' influence the research project (Thorne, 2008). However, I do believe being a fellow racialized person granted me access to information that participants might not have shared otherwise, and I do not take that lightly. In this way, it was important that I 
respect participants by sharing their stories; therefore I took detailed reflexive notes after each interview to examine my own use of self throughout the research process.

Next, my own experience around use of self and desire to highlight subjugated knowledges explicitly factor into the methodological process. Persons with other epistemological perspectives may have approached the study design differently, which may have produced different results. Lastly, my focus on subjugated knowledges means I have a personal investment in participants answering questions in ways that would be useful for how I am conceptualizing use of self. Hence, it was important that I phrased my questions clearly, and continually self-reflected to ensure participant voices (not my own) were at the forefront of coding, theme development, and the presentation of findings.

There were also some ethical considerations for this study, some of which have already been mentioned. The primary consideration is that this research was not intersectional in its design; therefore, it potentially missed other identity categories which inform how social workers use self. This is a limitation I discuss further in the final chapter. In addition, researchers before me have influenced the ways in which myself and the social work profession understand use of self. These understandings were influenced by dominant perspectives about the self, and how it can be used. Since my study is a response to previous writings on use of self, my work indirectly reinforces dominant ideas about the concept. In other words, just like the construct of 'Whiteness' does not exist without the concept of 'Blackness,' this project would not exist without dominant understandings of use of self. Hence, a major ethical consideration was to use 
in-vivo coding, and note-taking to ensure that my analysis was not simply a reaction to dominant ideals, but a purposeful upliftment of non-dominant ones.

\section{Chapter Summary}

This research study attended to trustworthiness by utilizing peer debrief and reflexive memoing from interviews throughout the analytic process. In place of member checking, I conducted a preliminary analysis of early interviews and gave later participants an opportunity to reflect on a synthesis of the previous group's experiences. I have also shown reflexivity by clarifying the experimental process from ontology and epistemology through study design, and explicitly describing my positionalities. Lastly, I have explained how findings were coded and presented in order to show adequate representation of participant experiences in a way that welcomed their counter narratives and subjugated knowledges. A demonstration of these components - trustworthiness, reflexivity and representation - allow me to show that findings are reliable and valid according to qualitative research guidelines.

This chapter also explained interpretive description, and tied its foundational underpinnings to the current project. These underpinnings include that studies are: conducted in a naturalistic setting that respects the ethics of participants; attend to the value of subjective and experiential knowledge for practice insights; focus on commonalities in the human experience as well as individual variance; attend to the time and context of human expression; hold that human experience is socially constructed; there is not a singular reality, but multiple constructed realities that sometimes contradict; and hold that the 'knower' and 'known' are inseparable and influence the research 
product. These foundational underpinnings are weaved throughout this research study. In the next chapter I review study findings, and provide narrative examples of the themes that arose during data analysis. 


\section{CHAPTER FOUR: FINDINGS}

Throughout the study, participants were very open about their practice experiences, and their conceptualizations of use of self. My values around subjugated knowledges meant that I incorporated participant language as much as possible in the development of codes and themes - language that can be clearly seen within selected quotes. This chapter is divided into three sections based upon my research questions which were: 1) What are the components of use of self as defined by BIPOC social workers? 2) How do issues of race and racism affect their perceptions of using self in practice context? and lastly 3) How have they used self in their practice and to what effect? Each section includes a discussion of themes and findings as they relate to my research questions. Table 2 offers a breakdown of the findings.

\section{Table 2: Findings}

What are the components of use of self as defined by BIPOC social workers?

- Self-Disclosure

- Bringing One's Whole Self

- Race

- Stereotyped bodies

- Heightened scrutiny in the workplace

How do issues of race \& racism affect perceptions of using self?

- Use of Self BIPOC clients - Workers felt more comfortable using self with other racialized groups

- Agency Context - Can facilitate one's comfort using self, and/or facilitate the social worker second-guessing their expertise

How have they used self in practice and to what effect?

- Modeling Change

- Affirming the Effects of Race and Racism

- Deepening Relationship with Clients 


\section{Components of Use of Self}

Interviewees named a few components of use of self, the first one being self-

disclosure. Interviewees as a whole conceptualized self-disclosure as any moment during an interaction with a client where they shared a story from their own lives as it related to the client experience, showed a legitimate reaction to a client (such as tears or laughter), and with BIPOC clients in particular, self-disclosure often involved commiserating about race and racism, and its effects on both the worker and the client. The ways in which study participants defined self-disclosure aligned with both my understanding, and those found in the literature - "statements referring to the past history or personal experiences of the counselor"(Anderson \& Mandell, 1989, p. 259).

When they spoke of their work with BIPOC clients, however, participants noted that they did not have to disclose race (unless they were White-passing) because it was often a shared visible identity. Be it verbal or non-verbal, many practitioners believed that when they self-disclosed, it made room for their clients to do the same. As a result, they built trust and safety more quickly which helped to advance client progress.

Next, some field instructors did not believe that use of self could be broken into components. For these workers, use of self meant bringing their whole personhood into the client-worker relationship in order to facilitate change. These practitioners believed that their entire personhood - personal, professional and otherwise - was brought into the room in session, and became a part of the self they presented.

Lastly, social workers shared that race was a component of their use of self. Practitioners noted that being racialized by society meant their bodies were stereotyped. 
As a result, some BIPOC social workers were mindful of not seeming too threatening or aggressive to clients or colleagues. Furthermore, the realities of racism meant that racialized social workers faced heightened scrutiny in their work.

\section{Self-Disclosure}

Participants talked openly about the positive impact of self-disclosure on their practice. Field instructors shared that for them, disclosure meant being direct and honest with service users. For example, one practitioner who works with adults and youth in a criminal justice setting noted:

I've learned that in working with the jail that they want you to be direct, they want you to be honest with them, they want you to tell them like it is...they respect you for it and they're willing to open up to you more. You're able to connect with them a little bit more when you bring that into the conversation...It's not what you say, it's how you say it. - P2, Black female, criminal justice, 10 years in social work

She went on to give an example where one of her clients had an oral hygiene issue, and she mentioned to him that he needed to take some time that day to care for his hygiene. She said that the participant was then able to explain that his mental health was affected by being incarcerated, and shared his appreciation for her letting him know. Though uncomfortable, this interaction gave her insight into what the client was facing, and she garnered his respect as well.

Another practitioner who works with youth said that she was very honest with her clients, not only because it was a part of her personality, but also because it was 
something her youth requested. In this way, self-disclosure became a part of her use of self in the therapeutic relationship. She explained:

I try really hard to be open and be non judgmental and open with them and honest. And because depending on the relationships I have with our youth, sometimes I can be really real with them and like, "Hey, do you want to know what I think about this? I think this is a shitty mistake that you're making. You know, I'm real with them, and I know that my training doesn't really say that. But it just depends on the relationship that I have with the youth. Because some youth will say, "Tell me the truth. What do you think? What is this decision I'm making?" I was like, "Okay, I'll be real with you." - P10, Latinx female, CYF, 10 years in social work In this way, when participants self-disclosed, they found that their clients were more likely to disclose as well. Many noted that self-disclosure gave them a chance to share a bit of their own story, which made clients feel they could safely share their story as well. One practitioner who works primarily with BIPOC populations shared that in her private practice she has:

...many clients who have said that they feel like they can tell me anything, and it's because I've been willing to share an experience with my child or an experience where I have not been successful, and I'm very transparent, if that makes sense - P24, Latinx female, mental health, 21 years in social work 
Through sharing stories, workers and clients were able to find common ground. It is through this common ground that social workers were able to strengthen their relationships with clients. One male-identified social worker talked openly about a time when he utilized self-disclosure to connect with a young African-American client who was resistant to treatment because he did not think the social worker could ever understand his particular experience. The social worker explained:

A lot of my clients are not White passing. So to us, we find comfort and strength in the loss of privileges in society, but together it's a strength, it's adding privilege, it's like sharing an understanding of difficulty and understanding of... turmoil and struggle to build connections. - P14, South Asian male, CYF, 10 years in social work

Thus, self-disclosure allowed the practitioner to find common ground, and strengthen his connection with the client. When asked I asked this social worker what benefits he saw to his practice when he self-disclosed and found common ground he noted:

Well, the benefit is my clients thriving, clients meeting their expectations, their goals, not mine, they're meeting their own... Another one, very simple one, they come back, they come back and they keep talking... People underestimate how important that is. That your client comes back. Your client communicates with you. - P14, South Asian male, CYF, 10 years in social work 
The phrase, "my clients come back" illustrates the value this social worker found in self-disclosure: it helped him to find common ground, which built trust and safety in the therapeutic relationship and most importantly, allowed him to more quickly help his client achieve his goals.

It should be noted that for the field instructors I interviewed, their selfdisclosure took various forms; sometimes they simply shared their joy around a TV show their client also liked and sometimes they engaged in more deep and heartfelt conversations about topics like motherhood and race. Again, the selfdisclosure was done to build common ground and build trust and safety in the therapeutic relationship. One practitioner working at a high school shared that she has had:

...a lot of conversations with students just around random things that teachers or other students have said, and then we'll go off on a tangent about food in different cultures, and we'll talk about cooking, or something, and I'll end up connecting with them in that way. - P11, South Asian female, education, 6 years in social work Another social worker explained that she has self-disclosed around motherhood. As a relatively new mother, she found that motherhood provided increased insight into the maternal experience, which became useful in her interactions with clients who are also mothers. She noted:

I feel like I've been able to connect more deeply with my clients that are moms, specifically experiencing postpartum, whereas they might not feel 
as connected to themselves, as connected to their child... Yeah, because now it's not just like a knowledge, from something that I read or being an auntie, it's really like I have physically, mentally and emotionally been through that, so we can really... I can share what my experience has been. I can share. I can understand. - P15, Black female, mental health, 12 years in social work

With a shared understanding of the maternal experience, this practitioner was better able to support the mothers and families she worked with. A key perspective given by a number of field instructors was that disclosure was necessary for clients to feel safe in the therapeutic relationship, especially clients with a trauma history because withholding information can become a tool for power and control. One field instructor who entered social work with years of experience in addiction services noted that "information is power." She explained that when a client asks personal information to their social worker, they are assessing for safety:

What it is like in hindsight is it's the trauma is coming up, and they're trying to decide if I'm safe and I'm not giving them anything to make them think that they're safe. Like nothing about me. And I'm saying, I want you to tell me all about you. And that's power. That information is power, right? And so the mutuality of disclosure, I think also is a mutuality of power. - P22, Mixed race female, medical, 2 years in social work 
This idea of a "mutuality of power" in the client-worker relationship was echoed by another participant with over 20 years experience in the social work field. This social worker shared that in her professional experience, self-disclosure was an important part of work with Black and Latinx clients because of the racial trauma they may have experienced. For example, Black and Latinx clients are not always believed when they share racial incidents, and may also be judged based on social norms and stigmas. Thus, for this social worker, self-disclosure was required for Black and Latinx clients to develop trust and safety in the workerclient relationship. Furthermore, when the therapist self-disclosed, the client is alerted that they could be vulnerable as well because people need to know "who they're talking to." She explained:

One thing that I know and I believe to be true, especially AfricanAmericans, but I believe it's also the case for Latina, Latinx culture, is that...we need to know, I need to trust you. We don't trust a lot. There's so much has happened to us in our history that trusting a person that I'm gonna divulge all this deep, all this historical information, all the stuff about my family and my background and how I grew up, I need to know you, I need to trust you, and that trust is... It needs to be reciprocated. They need to know a little bit about me, and I certainly don't divulge all the details of my experiences, but the general kind of concepts of those is enough for them to feel like they know who I am, and that is what creates that cornerstone, that relationship, through which my interventions...can 
jump off of because any of the interventions that I use or strategies I might use won't do a bit of good if they don't trust. If they don't have a relationship with me, and black folk need to know who they're talking to. P23, Black female, mental health, 22 years in social work

\section{Boundaried Self-Disclosure}

While interviewees talked about self-disclosure as a component of their use of self in that it offered an opening to build common ground with participants, and was necessary when working with survivors of trauma, including racial trauma, field instructors were also clear that their self-disclosure had an ethical boundary. For instance, one practitioner explained that she had a rule about self-disclosure where she did not ever share an issue that she was still working on for herself:

...my rule about self-disclosure is that I will discuss anything about myself that I'm not currently working on, so if I'm working on it... Then that's about me, and it's not an appropriate place for me to talk about it. But if I'm in class or I'm working with a student, an MSW student, or if I'm working with a client even, then I'm gonna disclose. And as part of me, I come from a belief system that if I can talk about me, that helps build rapport P22, Mixed race female, medical, 2 years in social work Another ethical boundary participants shared was that self-disclosure was used if it would benefit the client in some way; mainly to help with client progress. One field instructor with 14 years of experience working with children, youth and families shared that she avoids self-disclosure that could lead to clients being her caretaker: 
There's times when I'll share experiences but only share experiences in a way that brings the client forward. I don't just share a lot, because it's not about... because you have to be very careful in sharing not in a way that they start caretaking you. - - P3, Mixed race female, CYF, 14 years in social work

A field instructor working in a medical setting was very careful about her self-disclosure because she did not want to distract from the client work, but when she did self-disclose it was to uplift clients when they felt most challenged:

I don't necessarily share my personal experience with the client as it relates to that, but I use that in terms of how I help them to be able to actually see that there is some light at the end of the tunnel, and what you're dealing with right now today is challenging, but there's a way through. In terms of giving hope, because I think that's important, and that we each have strength. - P1, Black female, medical, 30+ years in social work

In this way, context dictated what and when field instructors selfdisclosed. For instance, one social worker shared that she senses what the client may need in that particular situation and pulls from those parts of self to disclose. She explained:

So what I look at, what I do is, I bring other parts of me depending on the situation, that's stronger. If someone's talking about racism, I'm thinking about my experience around racism and how I process it and give ideas 
and ways to deal with that and...when someone is dealing with depression, look at times when I dealt with depression, how do I bring that piece in there? - P3, Mixed race female, CYF, 14 years in social work

It is worth mentioning that there was one participant who explicitly named that she found verbal self-disclosure to be a distraction to the work. Instead she named empathy in her use of self. About self-disclosure she remarked:

I feel it brings in the therapist in a way that they don't need to be in the room that I think the counter-transference is incredibly important and what they portray as the therapist in the room and your natural interactions, but to consciously bring an additional layer in, to me, changes the dynamics, and I'd like it to be the client's experience. - P16, Mixed race female, mental health, 12 years in social work

At the same time, she mentioned that she has connected with a student intern over having a child the same age, and that the COVID-19 health crises had complicated issues of self-disclosure because work now happened in the home: ...we are all experiencing the same trauma together, that's really played a part and just really empathizing with people, but sharing that it's difficult, and I'm seeing my child in the background...So I guess I've been forced to be more open than I normally would.

\section{Bringing One's Whole Self}

Next, when asked about their use of self, some interviewees stated that it was difficult to separate themselves into components, therefore, they brought their whole 
selves into their work. A Native American female participant with 10 years experience in sexual assault and domestic violence services brought in the idea that self is greater than one person. She stated that her community values made it so that self was about "..my family, my community, seven generations forward and seven generations back." Another practitioner pointed out that it was impossible for her to separate her personal self from her professional self; in fact, both informed her practice experience, and that using self meant bringing in all aspects of her personhood - personal, professional and otherwise. She believed it was false to assume social workers can separate 'self' into components:

I think I put all of me into the field. I don't believe you can separate that. I don't think that any of us do. I mean, we give the illusions that I can only bring parts of me, and you can't, you bring all of you into the session, and everywhere that we go. - P3, Mixed race female, CYF, 14 years in social work

One participant was very clear that she used all of herself when she came to session and was very aware of its importance to the worker-client relationship, and to client progress. She stated:

I think for me personally, I use all of who I am in terms of how I show up and engage the folks...I'm very conscious, very aware, very proud of the fact that I am this African American woman that is residing in this community. As a result of that, I bring that into the room. - P8, Black female, housing, 21 years in social work 
"Using all of who I am" was particularly relevant when BIPOC social workers met with clients from historically marginalized racial groups. An interviewee doing culturally specific mental health work named how her personal life influenced her work because she was the work - ie. race influenced her client experience just as much as it influenced hers. She elaborates:

My own personal experience in this world as a Black woman, it's definitely influenced how I do my work and how I engage...Everything is about relationship and community, and that's not what school teaches you [which is] to separate yourself from the work as much as possible. And for me, I am the work. - P15, Black female, mental health, 12 years in social work

\section{Race as a Component of Use of Self}

In addition to self-disclosure, and bringing one's whole self to the work, field instructors also named race as a component of their use of self. For many of the BIPOC practitioners I interviewed, there was an understanding that racism was a reality; one that informed their social, cultural, and interpersonal relationships. In its pervasiveness, racism also informed their professional experiences as social workers. One practitioner powerfully and clearly explained this idea:

When you experience a lifetime of oppression, I think you have two ways of going.

You can either be angry and upset about it and in pain, or you learn how to move forward and find your worth within it. So because of that, I'm finding my worth 
within it and then I share that with people. And race is always an issue, whether the person sitting across from me is black or not, race is an issue. And you think that it's not, this whole world is based on racism. - P3, Mixed race female, CYF 14 years in social work

Because "race is always an issue" it factored into how BIPOC social workers were read by clients and colleagues which then affected their use of self. A Black male interviewee who works in education felt that it was difficult to be both a professional social worker and a Black man because of stereotypes about Black men. When clients and colleagues believed those stereotypes, he had little control over his use of self because it became about client assumptions, and not his authentic self. He shared:

For me, it's just, again, it's a constant struggle and it's a constant push and pull all the time, just as a professional, a black man, it's a constant push and pull to like just show up as myself and just be myself. - P26, Black male, education, 9 years in social work

Another social worker agreed and went as far as to say that when it comes to use of self, "I don't get that privilege, I don't, it's not my use. It's maybe acceptance, maybe. Like do I accept people using me?” (P14). In other words, for him, use of self was about what other people assumed, which did not allow room to actively use self. This comment directly connects with the two specific ways race factored into BIPOC social worker use of self: their bodies were stereotyped and they faced heightened scrutiny by clients and colleagues. 


\section{Stereotyped Bodies}

Given the realities of race and racism, participants stated that the first way race factored into their use of self was that their bodies and movements were perceived as threatening or aggressive based on stereotypes about their race, language or culture. The following quotes are from two different Black men who shared how their bodies were watched during interactions with clients and colleagues. They both were acutely aware that their Black male bodies were socially read as dangerous, and both attempted to work around those stereotypes through dress and body language. Still, there was an understanding that their racialized bodies represented more than just themselves - it also reflected social assumptions about Black men. They expressed:

When I'm teaching in front of a classroom, I find time to sit down in front of the class because I know when I stand up that's the image that they're hearing from me. They're already in defense when I stand up so I sit down a lot of time. When a student is angry, I'll let them stand, I'll sit because otherwise I have that threat. Or same thing with a client. When I'm with a client I'll sit most of the time, even if they're standing up, I'll sit down to even out that power because their unconscious belief system is running wild, and so I have to counteract that. I wear a tie to also counteract those stereotypes about black men. And I dress for school because if I don't dress for school, they automatically have a stereotypical belief about me and I'm already fighting twice as hard. The one year I did not dress and wear a tie, was the one year I got the worst student evaluation, and they 
said I was a danger because I was talking about racism, because it was a social justice class and I was talking about racism and the impact of religion in colonization. - P4, Black male, mental health, 19+ years in social work

I notice when I'm in an interaction, knowing, acknowledging I'm a Black man, I will literally change the tone of my voice...And let's say I'm working with a White client or a student or White colleague, like I notice the tone of my voice will totally change, I'll be more soft and gentle and all those things, because I feel like if I'm talking like this... Or even sometimes when I'm my real [name], I feel like it's gonna be a threat to them, or they're gonna feel like I'm aggressive, or they're gonna feel like I'm intimidating or something like that, and I do that all the time, and it's funny because it was an unconscious decision, I made.... I'm mindful of my hand gestures, I'm mindful, I'm mindful, even basic stuff like I'll cover up, I don't want my shirt, my polo shirt or anything to be like unbuttoned... I've been noticing a lot of this stuff because I don't want them to perceive I'm this sexual predator and so I'll button my shirt up or I'll turn the screen up so they can just see my face. It's crazy. Yeah, it's crazy. - P26, Black male, education, 9 years in social work It was not only Black men who named the impact of their racialized bodies on use of self. Two Black women who worked in criminal justice, and had a combined total of 22 years of social work experience, felt that some clients and 
colleagues found their Blackness threatening, and in this way, race became an aspect of self that they were acutely aware of in their professional practice, and was a consideration when they engaged with clients:

I just have to say, folks are really uncomfortable with my Blackness, my natural hair, not really uncomfortable, but I meet folks regularly who have a different view of who I'm going to be. And I'm okay putting that in the room and before we even experience that because when I didn't then I later found out that was a barrier, right, or a hindrance for folks - P6, Black female, criminal justice, 18 years in social work Some people might say I'm loud, some people might say I'm aggressive, intimidating, where I've seen people outside of my race do the same things and they don't get labeled with those things. We have to deal with that $\mathrm{P} 2$, Black female, criminal justice, 10 years in social work One Latina participant articulated that after staff meetings, co-workers would approach her to say that she too aggressive with her movements and comments to the group, though she articulated to me that she was simply participating in the meeting. Eventually, she started to check in with colleagues after meetings to learn how her statements and body language were read, but the oversight became too much:

I got conditioned that after staff meetings I would ask my co-workers, okay, what did I do wrong? What should I do next? They would tell me just, don't use your hands. Don't be so bold and just stay quiet, and I'm like 
that, okay. And then after a while I was like you know what, this is some west coast shit. I was like, I can't...I'm tired. This is who I am. - P18, female, mental health, 5 years in social work

Another Latina social worker in an education setting also found that she was stereotyped and her comments policed. She expressed frustration that her insights were overlooked by her dominant identity peers, and when she tried to offer perspective on how to better meet the needs of BIPOC clients, she was stereotyped as aggressive:

And that's one thing that I've noticed is that there are a lot of strong Latina women that are trying to advocate and then, like I said, we're then presented as angry... and then sometimes a White woman will say the same thing and they're woke for having said the same exact thing and they're like, Oh, she gets it, like, Oh yeah, yeah, let's do that. I'm like, I just said that two minutes ago. But mine seemed too aggressive, but theirs seems like it's the right thing to do. - P20, Latinx female, education, 6 years in social work

\section{Heightened Scrutiny}

In addition to their bodies being stereotyped, the second way race factored into field instructor use of self was that they faced heightened scrutiny in their work. Meaning, they felt that their interactions with clients were watched more closely than those of their dominant identity colleagues - "people were looking." This sense of always being watched did not deter interviewees from engaging in 
hard work, including work around racial justice at their agencies. One field instructor stated:

If anything, I think I'm probably more heightened because I feel like there's a level of ... I think it's real and some of it is what I perceive, that there's a heightened scrutiny that I'm aware of. So I'm trying to make sure I don't fuck up. You know what I'm saying? I'm making sure that if I'm going to do something that I do it well because I feel like people are looking. So I bring all of that in terms of how I kind of show up and I think I bring that into my job. - P8, Black female, housing, 21 years in social work

At the same time, the heightened scrutiny they faced was exhausting because they had to focus on the work as well as how their race was being perceived in the context of the work. This awareness of facing extra scrutiny in the work definitely affected practitioner use of self. One White-passing field instructor was open about how heightened scrutiny due to race made her want to shrink and not use self in her work:

So I pass, I pass as White. So it's kind of hard when I tell people that I'm Asian, I've experienced racism, I've been called names. And it's really hard, it's really hard to show up and use yourself because you wanna... You kinda wanna shrink... You kinda wanna be like, Okay, I'll stay in my lane - P19, Mixed race female, CYF, 2 years in social work 
Others were open about the emotional labor involved in trying to bring self into their work with clients and colleagues when they were under heightened scrutiny due to their race. Some participants found it too laborious and demanding to bring their authentic selves to the work because of constantly having to prove to colleagues they knew what they were doing, and what they were talking about when it came to their work with clients. Two Black practitioners explained the exhaustion:

It's tiring. It's just totally, I feel so exhausted because I spend so much of my time just fighting just to be myself...it's almost like now I'm learning and I'm developing, and then I'm also, I'm developing the language to explain what's going on and in that, it's just exhausting. It's so so exhausting... We gotta do better. We have to do better. It's necessary. P26, Black male, education, 9 years in social work Sometimes I find myself having to be able to prove that I actually know what I'm talking about a little bit more than maybe someone else might have to, who's not of my race. Do you know what I mean? That was something I had to, have to, deal with. - P2, Black female, criminal justice, 10 years in social work

\section{Race, Racism and Perceptions of Using Self}

Given the fact that BIPOC social workers named that their bodies were stereotyped and they faced heightened scrutiny, it is no surprise that race and racism affected their perceptions of using self. Interviewees expressed that race influenced the 
way 'self' showed up in their relationships with clients - use of self came more organically when working with BIPOC clients.

In addition, the agency context played a significant role in how comfortable BIPOC field instructors felt using self at their agencies. Specifically, when agencies affirmed their identities, practitioners felt comfortable using self at work and in their practice. In affirming organizational spaces, practitioners did not feel tokenized, had access to promotion opportunities at the same frequency as their White colleagues, their voices were heard, and they had co-conspirators in their equity work; meaning, they were not the only ones pushing the agency forward. Alternatively, when agency culture was not inclusive of practitioner insights, they were prone to second-guessing their expertise, and were less likely to use self to the benefit of their practice.

\section{Agency Context}

A number of interviewees explained the value of being at an agency where their voice was celebrated, and their input warmly received. One social worker expressed how happy she was to be working in an affirming environment because it made it more comfortable to show up as her unique self and use that self when working with clients. She noted:

I'm so lucky to be able to work in a community where my identity is so celebrated, multiple of my identities are celebrated and centered in the work and in the programming, and although it's not for me...I get to build the skills with young people who share my identities...and I just have the connections and relationships with them which makes it so so easy to want 
to show up in that way and to continue to get to engage in the community that is work and work that is community, I think is a really big, big piece, and so I'm so willing to show up as my true, most unique self, because I think I've been... My identities have consistently been affirmed in these spaces. - P13, Mixed race female, CYF, 10 years in social work Another participant worked at an agency with children and families for many years before eventually opening her own private practice. Even then, her agency was able to retain her expertise in supervising social work students and have remained very supportive of her personal and professional goals. When describing her organization she noted:

I felt honored, I felt seen, I felt accepted...they value what I do. So here I am, African-American black woman, lesbian, I'm out at my job. They all know who I am, what I am, and I feel like I'm seen there. I have, I have a really good experience there. - P23, Black female, mental health, 22 years in social work

One worker summed it up best when she said, "because I was in an agency that valued my racial identity and my knowledge that came with that, I was more confident to be able to use it [self]" (P3). Therefore, agency context informed how comfortable workers felt using self.

Alternatively, when field instructors were in agencies where they felt isolated, their perspectives were ignored, and they experienced tokenization, they were prone to second-guessing their expertise. When practitioners second-guessed 
their expertise, they were less likely to use self with their clients because they lacked the confidence that their use of self would be beneficial to the workerclient relationship. For example, one participant spoke about being racialized as Latina upon entering the United States and the concerns she had early in her career when working with White families; concerns which affected her use of self:

I think that historically, I went through a process where I did not understand why some Caucasian families really wanted to come to work with me, that was long years ago. I would say, why you wanna come to work with somebody who has broken English and really, I minimize myself. Part is a history of my own family and part is being so Latina since I arrived in the United States, they made me Latina, and I think unconsciously, there was a sense of what would I offer you? - P21, Mixed race female, mental health, 30+ years in social work Another social worker spoke of two experiences she had, one where she worked in an affirming space and another where she was the only BIPOC person in her role. She shared that in the affirming space she was surrounded by other Latinas who also spoke Spanish. There, she did not feel as she explained, "hypervigilant" but when she transitioned to working at an agency where both the clients and providers were White, she struggled to use self. She stated that in that space: 
I never felt like I could be myself, I always have to feel like I had to know what I was doing. I had to have that like, I'm an LCSW. Yes, believe it. And when parents came in even more of a layer, Do I really know what I'm... I'm doing?... And I wasn't being able to be myself in the process, and I think that was the hardest piece of... I always felt drained at the end of the day, I never felt like I had done something that I felt good about, or that I was being... Just my genuine self there, I'd always have to be questioning whether I knew enough, and felt a lot of doubts about myself in that space as well. - P20, Latinx female, education, 6 years in social work

\section{Use of Self with BIPOC clients}

Just as the agency context mattered for how comfortable workers felt using self, participants also explained that the client context - namely if their clients were BIPOC or not - influenced their use of self. A number of participants felt that their shared racial identity with BIPOC clients made it easier to use self because they were less concerned about being judged or perceived as unprofessional/unqualified. One participant clearly articulated that 'self' shows up when working with members of her own culture because she was less fearful of racism within the client-worker interaction:

I think myself shows up differently and has a lot more boundaries than maybe when I'm working within my own culture because I'm not experiencing that component of it. I'm not getting racism from Black folks 
that I'm working with. They're not making assumptions about my intelligence or my abilities in the same way that I've experienced with White folks. So that and how I show up can look really different. And I don't do a ton of necessarily self-disclosure with White folks. And partially because so much of it tends to be about how race shows up for people. It doesn't feel the same. It's not the same type of conversation I need to have with them because the system is not set up for them to fail in the same way. - P12, Mixed race female, housing, 20+ years in social work

Similarly, a practitioner working in mental health shared that she felt more comfortable using self with BIPOC clients because there was an instant connection, and less professional scrutiny:

I feel much more comfortable and more at ease because if I slip up. I know I'm okay in slipping up, but for working with White people, it's like you gotta be on your A-game because not only are you a social worker, but you also carry a color that is always being put down or discriminated on and seen as less educated, so I'm not saying that I don't bring my A game with the minorities, but it's just that professionalism is much higher and intense...rather than with the minority community because you have that connection, so I don't have to prove anything to the minority, 'cause for them it's like, Wow. You have a person of color in that position. They feel 
good, they feel like, Yeah, I could connect. - P18, Latinx female, mental health, 5 years in social work

This worker also gave an example of how she connected with one client because they were both from racially marginalized groups, and as a result, both felt comfortable self-disclosing and bringing their authentic selves to the session. She shared:

I had this one man, he's still my client...He's an African-American gentleman, gay. And when he saw me and he was like, Oh, thank God I got you. And I was like, Oh, okay. And it was so funny 'cause we was just chatting in my office about his regular stuff, and he was just like, Oh, I'm gonna have a good time with you. I like this, I'm comfortable, I love your accent. You're not from here. And I just like, Okay, cool. And then as you started talking it was just a connection of the color, that really just helps in... it soothed the whole therapy session for him and I continue to have him. - P18, Latinx female, mental health, 5 years in social work

\section{Reasons for Using Self}

Given that scholars such as Mandell (2008) have said that use of self is becoming less relevant, I was curious to learn the reasons why practitioners used self. Findings indicate that field instructors used self to model that change is possible, to name and affirm the effects of race on their client's experience, as well as deepen their relationship with clients. 


\section{Modeling Change}

When working with clients, field instructors understood that a key part of their role was to advance client progress. They also understood that clients did not always have models of what the change process looks like, and the end result. Therefore, one way social workers used self in practice was to model to clients that it was possible to achieve their goals. One social worker shared that she uses her personal experience to highlight that change may be difficult, but it is not impossible:

I try, honestly, $100 \%$ to just be me, and I told them like I can kinda give them background on who I am and where I grew up, and a lot of normalizing other stuff would be with my own personal experience as well. In my personal life as well, but not going into details...It makes them know like, Okay, they're a human, just because they're sitting on the other side doesn't mean that their life is perfect...So just a lot of normalizing, but not really in that therapeutic wording, more of just authentic of, this sucks. It's gonna suck for a while, but we can do this together. - P18, Latinx female, mental health, 5 years in social work Part of modelling change also meant being aware of personal challenges, and taking time to heal before attempting to aid a client who is navigating a similar issue. One interviewee doing culturally specific work in mental health shared:

We carry stories of trauma, we carry stories of being minimized socially with historical traumas and so many different things, and bringing that to our awareness, is that we have to heal ourselves in order to support the 
healing of others, but something that I think is hard, that definitely shows up as the sense of self, if you're not aware, the whole idea of the countertransference, transference, concepts that are part of it, and then being aware and having a space to bring that in. - P21, Mixed race female, mental health, 30+ years in social work Another added that it is impossible to model change, if the worker has not acknowledged their own issues because it can cause further harm. Thus use of self requires an understanding of the workers' own limitations. She noted:

I can't acknowledge in others what I can't acknowledge it myself... Period, right? Like if I haven't worked on my mommy issues and you've got mommy issues, I'm gonna deflect because I can't go to that place for myself, so I certainly can't go there with you. - P22, Mixed race female, medical, 2 years in social work

\section{Affirming the Effects of Race on Client Experience}

Another reason why social workers used self in practice was to affirm the effects of race on the client experience, especially as it related to shared understandings of racism and marginalization. Many believed that their unique insights into what it means to be a BIPOC person in society allowed them to use self with the goal of naming and affirming the realities of race and racism. Specifically, workers found that when they call out racism in conversations with clients, their clients felt supported and understood, which enhanced trust and safety in the relationship, and advanced client progress. One practitioner who has worked in culturally specific services as well as in governmental 
agencies shared that she does not shy away from talking about race because we live in a racist society:

I'm still using everything that I've learned, from my experience and how race will make a difference. I mean, I used it all the time and was very frank with some young people who are people of color who are experiencing racism on a daily basis.... Because it's going to happen. And if we shy away from that reality, it's not supporting them at all. And so until we live in a society that's not racist, that we don't have systematic racism, I'm not doing them support by not calling it out for them. It offers them more support in the end... And I have an obligation to me because of my lived experience, because I'm a person of color, have that ability to talk with them truly about that. - P3, Mixed race female, CYF 14 years in social work

Another worker succinctly explained that naming structural racism has a profound effect on her engagement with clients:

I think with the piece around the structures, and institutions, and the racism that is inherent in those that I've seen so many people just have this like sigh of relief when it's said out loud that like it's that gas lighting. People start to make you feel like you're actually crazy because you're experiencing these things that they're not seeing or at least acknowledging that they see. And so, being able to say like, "This is real and I hear you, and that's true." There's this like, "Okay, now I can actually breathe and 
focus because I'm not beating my head against a wall about this." So that I found really helpful too. - P12, Mixed race female, housing, 21 years in social work

Another participant gave a clear example of how she was able to affirm the effects of race on the young people in her organization by intentionally asking BIPOC staff to engage with youth who are having difficulties in the space. In this way, these BIPOC workers used self - specifically their racialized bodies - to intentionally intervene in order to create a sense of safety for the BIPOC youth seeking services at the agency. She shared:

I think that's been really helpful for us, especially as social workers of color in our organization. We have been more intentional about engaging if there's a youth who is a youth of color who has threatening language or has been really threatening in this space, it's been really intentional that a person of color, a worker of color needs to approach that person outside of this space of, "Hey, let's talk. What's going on?" Because what I've noticed is sometimes, especially White men in our organization, aren't aware of their identities and don't realize how off some of our youth can feel, especially youth of color. I don't think they have that awareness. Maybe we should intervene. Maybe we have a little bit more sway. That's been interesting for us for sure. P10, Latinx female, CYF, 10 years in social work 
She went on to share that the youth responded very positively to being approached by BIPOC staff members, further illustrating how social worker bodies factor into their use of self.

\section{Deepening Relationship with Clients}

The final reason why participants used self in practice was to deepen their relationship with clients. When practitioners used self, they could better relate which advanced the therapeutic relationship. A mixed race worker in education stated:

I'm good with like being super, super relational. That's how, that's how I roll, and my people and my culture. And so, sometimes I might share a piece of my story on a pretty deep level if I'm feeling like this is a real turning point for them - P5, Mixed race male, education, 11 years in social work

One specific tool interviewees used to deepen relationship with clients was to approach the work with humility and a non-judgemental attitude. This approach was particularly interesting because there is a clear insertion of the social workers' values into the helping process - values around de-centering traditional notions that they were the expert. Furthermore, the insertion of humility and a non-judgemental attitude into use of self seem to be informed by worker experiences being scrutinized at work - there was an explicit desire to avoid replicating this pattern with their clients. One participant stated that his approach was about loving his client no matter what; when he approached the work with an open mind he was better able to use self and show up fully: 
The saying I have is "out love them, out last them," and I think that allows me to show up, and not be burnt out and be super strong for these people...Even if I'm not verbally judging, I'm not going to even think about being frustrated with them, it's like, I just have to show up so authentic and so positive. Just knowing, I can just love them, literally love them to their core. That's one piece, right? Because that doesn't have the ability to facilitate change but it gets me into the mindset to do it. - P05, Mixed race male, education, 11 years in social work For interviewees, part of building relationship with clients involved using terms clients understand, and not trying to be a professional expert:

I don't carry myself with very psychological or academic terminology, I try to bring it down to layman's terms, and if I must use a word that is difficult to understand, then I take my time to explain it. And someone told me, you humanize things or you make them normal, and it's easy to talk to me about, so that's the biggest benefit I have. - P24, Latinx female, mental health, 21 years in social work

Workers also recognized the power they held in relation to clients, which made humility and non-judgement central to their use of self, and central to their ability to build relationships with clients:

I recognize the position that... Of influence, that I have over people, and so always trying to be humble, be relatable to them on some level, so you can develop that trust, 'cause I think that's how you effectively do that good 
social work with them when you show up in that way. - P19, Mixed race female, CYF, 2 years in social work

...sometimes you're training to be this person that is the expert and like you have all the expert in the world. But from my way of working, and working from an anti-oppressive model and working from a place of, "I'm not the expert", I try really hard to make the people that I serve see their own choices. - P10, Latinx female, CYF, 10 years in social work BIPOC social workers used self for a few reasons. They found that it offered room to model to clients that change was possible in their lives, to affirm the realities of race and racism as they affect the client experience, and to deepen relationship with clients. When practitioners used self in these ways, it allowed them to better support their clients, and move through the change process more quickly.

\section{Chapter Summary}

Study participants named a few components of use of self: they shared that selfdisclosure was important to their practice, some noted that use of self meant that they brought their whole selves into their work, and field instructors shared that race factored into their use of self because their bodies were stereotyped and they faced heightened scrutiny in their work. In addition, findings indicate that race and racism affected perceptions of using self because participants showed up differently with BIPOC clients compared with White clients. With BIPOC clients they were less concerned about racism, which made them feel more comfortable using self. 
Agency context was also important for use of self - when in an affirming agency participants felt comfortable using self but when in a non-inclusive environment, they were less likely to use self to the benefit of their practice. Finally, the effects of use of self included the ability to model to clients that change was possible, to affirm the effects of race and racism on client experience, and to deepen relationships with clients. 


\section{CHAPTER FIVE: DISCUSSION}

Participants were forthright about the multiple ways race influenced their use of self - from the ways their bodies were policed and read, through their increased comfort using self with BIPOC clients due to decreased concerns about racism. Additionally, incidences of stereotyping and scrutiny informed worker feelings that their personhood (or self) came second to societal representations of their racial and cultural identities which then affected their ability to use self in practice in order to facilitate client change. Study findings highlight the importance of decentering Whiteness when discussing social work concepts such as use of self.

Two Black male participants whose quotes are detailed in Chapter 4, offered clear examples of how use of self was affected by racialization. In addition, a Black female working within the housing field shared: "I'm making sure that if I'm going to do something that I do it well because I feel like people are looking. So I bring all of that in terms of how I kind of show up and I think I bring that into my job" (P8). This worker knew that she was being watched, and wanted to show her best in the hopes that it would be better for other BIPOC social workers.

Secondly, a Mixed race female working with children, youth and families explained, “...it's really hard to show up and use yourself because you wanna...you kinda wanna shrink" (P19). In this concluding chapter, I discuss the findings, integrate them with the empirical literature, explain potential implications for the study, review limitations and conclude with future areas of study around use of self. 


\section{Use of Self in Practice}

Practitioners found use of self to be a useful relational tool that allowed them to deepen relationships with clients and model that change was possible. They acknowledged the inherent power within the social work role, and in admitting that power, were better able to relate and uphold anti-oppressive principles. At the same time they were clear that use of self would not be possible if the worker had not spent time reflecting and processing their own histories and traumas. Otherwise, it could cause harm. One worker explained this idea beautifully when she said, "I can't acknowledge in others what I can't acknowledge in myself' (P22), and if one cannot acknowledge something, then they are not ready to help others do the same.

Social workers also shared that use of self was helpful, especially when working with other historically marginalized groups because it gave them room to name and affirm the ways race influenced client experiences. They spoke of the 'gas lighting' that can occur when marginalized groups share racist acts, microaggressions or experiences to dominant-identity groups and that experience is said to be inaccurate or caused by any reason but race. Many participants really valued the fact that as racialized people themselves, they had unique insights (subjugated knowledges) about racism's insidiousness, and they wanted to bring those insights to their work in ways that would allow them to connect, and affirm BIPOC client experiences. As one social worker stated, “if we shy away from that reality [of racism], it's not supporting them at all. And so until we live in a society that's not racist, that we don't have systematic racism, I'm not doing them support by not calling it out for them. It offers them more support in the end" (P3). 
Thus, some participants felt it would be a disservice to racialized clients if they did not affirm race and racism as part of the client experience.

In one of the few articles to ask social workers about their use of self, Liechty (2018) found that use of self allowed practitioners to relate to clients across culture, age and ability, and was a way to build the worker-client relationship. However, the assumption is that use of self remains consistent regardless of the race of the client. Findings from this study show that this is not necessarily the case; the practitioners that I interviewed shared that they felt more comfortable using self with BIPOC clients because of their shared racialized experience, which indicates that use of self is not always consistent across culture or race.

\section{Self-Disclosure as a Necessity}

Another finding that arose within use of self in practice was that a number of BIPOC social workers named self-disclosure as something they have practiced, and use often. They explained that disclosure facilitated trust and safety in the worker-client relationship. In his book on therapist disclosure and use of self, Weiner (1983) posits that self-disclosure and use of self "...refer to a type of therapy that takes into account the therapist as a fellow human being in relation to his patient: a situation in which the therapist offers more to a patient than professional expertise, but not his entire self" (p.2). In his understanding of disclosure, Weiner (1983) names that therapist self-disclosure is about showing the worker's humanity, and goes on to say that often it is less about the disclosure itself, and more about what it does for the worker-client relationship. 
Study findings merge with Weiner's (1983) point that self-disclosure advances the client-worker relationship, and highlights a shared humanity; participants routinely named connection and common ground as one benefit of using self. This stood out as a key finding because often the practice field is very cautious about social worker overdisclosure, especially because of potential ethical violations. Yet, participants believed that clients felt increased safety when there was disclosure, because it showed that the worker was a human being and not an emotionally distant expert.

However, Weiner's (1983) states that workers should not use their entire selves, which deviates from my findings. For some of the BIPOC social workers I interviewed, it was impossible to separate self. One participant explained, "I put all of me into the field...I mean, we give the illusions that I can only bring parts of me, and you can't, you bring all of you into the session, and everywhere that we go." (P3). I believe that some of the divergence here is due to participant racialized experience. While dominant identity practitioners might freely select aspects of self to disclose, race is a visible identity category that does not often require self-disclosure (except for White-passing persons). As a result, BIPOC practitioners have no choice but to bring their whole self to the work because often their whole self includes their own personal experience, and also the racial assumptions placed on them by society. Thus, it is almost simpler for some to bring the whole self to the work - race and all - than to ignore the reality of its existence in both the personal and professional sphere. 


\section{Race and Use of Self}

When asked about how race and racism factored into use of self, participants expressed that race influenced the way 'self' showed up in their relationships with clients. Though it did not always influence the work, social workers were acutely aware of their client's race. This makes sense as social work requires an awareness of the social structures and their impacts on experience (race is one such social structure); however, this racial awareness connects to use of self as some social workers shared how differently they felt working with members of their own community when compared to working with dominant identity clients. Findings imply that for BIPOC social workers, use of self may be filtered through their racialized safety assessment of the client interaction. As a result, when they were working with racialized clients they were more comfortable using self than when working with dominant identity clients because they were less concerned about racism.

Participants shared increased awareness of racism's impact on their own experiences also meant that when working with BIPOC clients they were likely to call it out and affirm the experiences of their racially marginalized clients. In this way, race influenced the 'self' workers used, and their level of comfort using self to benefit clients. In Chapter 2 I explained that according to Social Identity Theory, racial categorizations (in-group and out-group) can affect how the 'self' of a social worker is perceived (insider or outsider), which then impacts their ability to use self to facilitate client change. Thus, a social worker may feel more connected to someone of their same racial group, which informs their use of self. I also explained that race may be activated as a social identity 
in some spaces (ie. culturally specific services) and not in others (predominantly White spaces for example). The idea that there may be increased connection with members of one's racial group, and that race is activated (or even deactivated) depending on social identity, is clearly highlighted in this quote from a worker who worked in a culturally specific agency and felt very comfortable self-disclosing and using other aspects of herself in the work. Yet when she transitioned to a predominantly White space she did not believe she could truly be herself, and had to present as an expert which was draining: ...I wasn't being able to be myself in the process, and I think that was the hardest piece of... I always felt drained at the end of the day, I never felt like I had done something that I felt good about, or that I was being... Just my genuine self there, I'd always have to be questioning whether I knew enough, and felt a lot of doubts about myself in that space as well. - P20, Latinx female, education, 6 years in social work

Based on my findings, the client racial context of whom is sitting across from you in session matters for use of self, and so does agency context. The research literature on use of self has acknowledged that use of self is situationally-based (Jamieson \& Davidson, 2019) and generally informed by sociocultural realities (Reinkraut, 2008; Reupert, 2007; Reupert, 2008), but these sociocultural realities are not detailed. I have also not found any literature on agency context and use of self, but I believe this is another important finding because it places some of the onus of client work onto the agency. When participants in this study talked about their agency settings, they illustrated how perceptions of being an insider or outsider affected their use of self - 
when they were in organizations where they were valued and celebrated, there were little to no barriers to using self. A great example is when one social worker doing mental health in a culturally specific agency shared, "It's actually really comfortable...I know I can show up and do the work in the way that best serves that specific community" (P15). On the other hand, when BIPOC workers felt like an outsider, they felt constricted in their ability to use self to the benefit of their practice and were prone to second-guessing their expertise.

At the beginning of this dissertation I contended that Whiteness is so embedded within social work identity, values and knowledges that racialized social workers doubt their professional abilities and/or have others question their skills (Badwall, 2015). This point was highlighted in the findings when practitioners spoke of their insights being overlooked, and those of their White peers welcomed. Relatedly, Leary (2007) continues that it is not race that affects the interaction between a therapist and a client, but the process of being raced. The racialization of BIPOC social workers in this study meant that some felt more comfortable using self with other BIPOC persons compared with Whites. This is particularly interesting because either way, the worker is raced - they are raced as BIPOC by both Whites and other historically marginalized racialized groups. However, the racialization felt different depending on the racial background of the client. When they were raced by BIPOC clients, it opened up common ground, which strengthened the worker-client relationship; but when they were raced by Whites, it became a point of disconnection, which impeded their level of comfort using self to build relationships. I believe this is a really important distinction, and again highlights how 
race and use of self intersect.

Findings from this study offer clear support for Badwall and Leary's arguments about race and practice - participants routinely named the ways their bodies were raced, stereotyped, and subject to heightened scrutiny. They also named that they doubted their professional abilities within non-inclusive agency spaces, and felt affirmed in spaces where they could bring their full selves to the work. In general, these findings affirm the effects of structural racism on BIPOC social work practice.

For many of the social workers I interviewed, there was a double consciousness: an awareness of being a racialized person in society, as well as an awareness of one's role as a social work practitioner. This double consciousness can affect the ease at which social workers use self in order to facilitate client change. In particular, if social workers are constantly embodying two selves, it may take more effort to use self in practice. There were some participants who rejected splitting selves, yet still the social construction of race meant they could not separate themselves from the work because they experience racism and bias just as their clients do. As one participant named, "for me, I am the work" (P15). This brings to mind W.E.B. Dubois' (1999) explanation of the double consciousness, which beautifully explains what BIPOC practitioners experience when attempting to use self:

...this sense of looking at one's self through the eyes of others of measuring one's soul by the tape of a world that looks on in amused contempt and pity. One ever feels his two-ness - an American, a Negro; two souls, two thoughts, two unreconciled strivings; two warring ideals in 
one dark body, whose dogged strength alone keeps it from being torn asunder (p.11)

In addition to a double consciousness, field instructor descriptions of being raced and stereotyped connect with the tenets of Critical Race Theory. First, since race organizes society, it also organized the ways in which social workers practice. As participant 26 explained, “...race is always an issue, whether the person sitting across from me is Black or not, race is an issue...this whole world is based on racism." One consequence of structural racism in social work is that it makes it harder for BIPOC social workers to separate how race and racism affected them personally when compared with its professional effects because often they look and feel one and the same. It also means they are doubly aware of what 'self' represents as a racialized person, and which informs how they use that self in their work with clients.

Furthermore, since we do not live in a colorblind society with equal opportunity for all, interpersonal relations and use of self are neither color-blind nor equal across racial groups. This is illustrated in a comment by a Black female social worker, "Some people might say I'm loud, some people might say I'm aggressive, intimidating, where I've seen people outside my race do the same things and they don't get labeled with those things." (P2). For this particular social worker, her use of self was affected when her gestures and words were stereotyped as aggressive thus indicating that use of self is not colorblind but is informed by social constructions of race.

Next, the social construction of race influences the practice experience of BIPOC social workers. This is clearly seen when one participant explained that one way being a 
racialized person influenced his practice experience was that he always wore a tie "...to also counteract those stereotypes about Black men. And I dress for school because if I don't dress for school, they automatically have a stereotypical belief about me and I'm already fighting twice as hard" (P4). In other words, the social fear of Black masculinity meant that for this worker to show up and use self in practice, he had to be mindful of what his 'self' represented socially, and take steps to mitigate that impact (ie. wearing a tie) in order to be taken seriously in his professional role.

\section{Unique Contributions}

This dissertation hopes to contribute to the practice literature in a number of ways. First, it shows that for some BIPOC social workers, there is no separating self. Instead, their lived experience deeply informs their social work practice. Workers named how passionate they were about advancing racial equity and advocating for their BIPOC clients. This passion was certainly informed by their own experiences, and a desire to make things better for the next generation of social workers. Relatedly, this study contributes that for some BIPOC social workers, use of self was not something they had the agency to use because of societal understandings of what their race signifies. This is important because there is an implicit assumption within the social work literature that all social workers actively engage in use of self, but this is clearly complicated when social workers are racialized by clients and colleagues.

Next, a number of participants stated that worker self-disclosure was necessary for trust and safety in their relationship with clients. In addition, they held that withholding information was in fact a power play, one that could harm the therapeutic 
relationship and the work. While the social work literature includes conversations of power sharing as it relates to reflexivity and self-awareness (Fook 2002; D’Cruz et. al, 2007), it does not discuss power sharing as it relates to use of self. Yet in this study, participants shared that they had an explicit value around power-sharing (which they illustrate through humility and a non-judgemental approach) which became a tool of their use of self. I believe this is another important contribution to the literature on use of self.

Third, participants stated that for survivors of trauma, disclosure was particularly important as not to activate issues of power and control which would not be beneficial to the client. This is an important contribution because it goes against narratives that say therapists should not share aspects of their personhood with clients, and opens up room to consider more nuanced questions such as the context of the disclosure, its specific relevance to the case at hand, as well as how to repair any potential consequences that may arise if a self-disclosure is not well-received by the client.

Fourth, findings demonstrate that there are aspects outside of one's own personhood that influences use of self, namely how the agency culture affirms (or does not affirm) their expertise and perspectives. I believe this is a significant contribution to the ways in which we conceptualize use of self. If practitioners are saying that agency context helps dictate how much they pull from their personhood to facilitate client change, then we must think about use of self more broadly. It is not only about the person, but also the person in their environment. Thus, context is salient for clients as well as the social worker. 
Lastly, the social work literature only has a few articles that explore social work practice from the perspective of BIPOC social workers, none that are focused on field instructors, and none that specifically look at how these practitioners use self. Since field instruction is a role that is central to social work education, and students who have been supervised by BIPOC practitioners have reported feeling prepared to work with racial groups other than their own (Black et. al, 1997), social work must do more to highlight the subjugated knowledges of an important segment of the social work community. In addition to contributing to the literature in key ways, I believe findings from this project have several implications across practice, social work education, and research.

\section{Implications for Social Work Practice}

In this current moment where society is continuing to grapple with the murder of Black and Brown bodies at the hands of police, alongside an increase in anti-Asian hate crimes, it should come as no surprise that bodies also factor into use of self because they are often read through social scripts. Therefore, if use of self is truly about relationship, then there must be an understanding that relationships do not live outside of societal constructions of race and worker bodies become a part of use of self. Thus, when social workers include race in use of self it gives social workers - BIPOC and otherwise - the freedom to bring race into the room explicitly because it informs the experience of not just the client, but the worker as well.

Since their racialized bodies become a component of use of self for BIPOC social workers, I believe this implies that social workers should openly consider how they want to use their bodies in the work so that it is not a hidden component of their use of self, but 
an explicit one. For BIPOC social workers who may have been taught that to be professional social workers they must maintain an objective distance from race, this idea can be freeing. If race becomes an explicit part of the work, there might be less doubleconsciousness, which would allow them to focus on the work at hand, and not the work as well as what their bodies represent. Another benefit of bringing in race within worker use of self is that it addresses the lack of agency that can arise when BIPOC workers believe that they are not able to use self because of the social construction of race. When BIPOC social workers have agency to name race in their use of self, it becomes about their active engagement, and not solely societal representations.

A final implication of this study is that agencies must do more to facilitate worker use of self. If use of self is the social work instrument, agencies are a tuner. When workers are affirmed they become more attuned to use of self as a practice tool. To enhance social worker use of self, agencies must do their work on anti-racism so that BIPOC workers are not tokenized, and can bring their whole selves to the practice sphere; when workers are able to so everyone benefits - workers, clients, agencies, and the field as a whole. Agencies should also create and support spaces for BIPOC staff to gather and process race, use of self, and practice. In this way they affirm the impact of race on the worker's experience, which makes it easier for the worker to do the same for racialized clients.

\section{Implications for Social Work Education}

This study also has implications for the ways we teach about use of self within social work education. I have had the pleasure of presenting this research to a few 
different audiences - undergraduate social work students, field education leaders, and practitioners at a large area hospital. Overwhelmingly, each audience was most interested in how to communicate the complexity of disclosure to social work students. They were most concerned about students taking self-disclosure too far with clients, and causing harm.

My response was consistently that just as use of self is an instrument to be tuned, social work educators and field instructors should also discuss disclosure as a component of use of self that must be tuned. Field instructors in this study named that through trial and error they learned what to disclose and how, in order to best build relationships with clients and use self to facilitate change; self-disclosure was not a thoughtless enterprise. I believe that social work curriculum should include lessons on the nuances of disclosure as a tool to move the change process and worker-client relationship forward. These conversations should include explicit guidance about how to engage in repair work should a self-disclosure distract from client work. If a client retracts because of worker self-disclosure, this then becomes therapeutic information, and from there, the worker can have a conversation with the client about what went wrong, its impacts on their experience, and their preferences moving forward. In this way, even if self-disclosure was not used effectively, it still allows for growth within the client-worker dyad.

Just as Heyt \& Sherman (2005) named use of self as an instrument to be tuned, so is disclosure - one does not pick up a piano and instantly become a concert pianist. Therefore, it is necessary when discussing use of self and disclosure to leave room for practicing the art of the disclosure. In this way, disclosure becomes a part of the social 
workers toolkit to be used to clinically advance client goals. Self-disclosure should not be taught as something to be avoided, but as a useful tool to be embraced.

I have also named repeatedly that social work content often assumes that students are White and clients are BIPOC. This assumption means that when race is addressed in the classroom, it centers how dominant identity social workers should work with 'the other.' Instead, educators should include content and activities that reject this assumption about use of self and embrace that the race of the client and the race of the worker matter in the interaction. Classroom activities can include role plays on how use of self might present itself when working with members of one's own racial group, and how it may differ or stay the same when working with members of other racial groupings. Relatedly, activities can consider how assumptions about what constitutes 'client change' may connect with dominant assumptions and/or be informed by racialization. I believe these conversations will add nuance and complexity to the way use of self is taught, as well as how it is implemented in the future.

\section{Implications for Research}

Finally, this dissertation has a few research implications. Critical Race Theory (CRT) informed the way I theorized this project because it understood that race organizes society; the same society all social workers inhabit. As a theory, CRT has implications for research because it explains why race is pervasive, and in its explanation opens up the possibility of non-dominant ways of research (such as looking at subjugated perspectives and counternarratives). As social work researchers, counternarratives help to decenter Whiteness, which I think is necessary in order to advance anti-racist praxis, and to 
maintain the values of the profession - to promote social justice on behalf of historically marginalized populations.

There are also methodological implications to consider. The present study used an Interpretive Description (ID) methodology, which holds that research should be done to move the practice field forward, and should engage the wisdom of "those whose professional commitment embeds them in the field every day" (Thorne, 2008, p. 85). I found that as a practice focused methodology, ID fit perfectly with the aims of this project which was to uplift the subjugated practice knowledge of BIPOC social workers. While ID has its origins in the health sciences, principally nursing, it has implications for social work research as well.

As a field, social work aims to address barriers that affect the most vulnerable members of society. This means that research should be about uplifting marginalized voices in the hopes of making a more just society. By using an Interpretive Description methodology in social work research, I was able to zoom in on key informants and these key informants provided unique insights that now recast how we think about use of self in social work. This cannot be understated. Additionally, when used correctly, interpretive description gives researchers insight into the practice sphere which I believe can help bridge the research-practice gap because it increases conversations between practitioners doing direct-practice work, and researchers who might be more distanced from practice realities. Interpretive Description also has implications for researcher use of self. 


\section{Use of Self in Research}

Interpretive Description sees the researcher as an instrument of interpretation whose aim is to uncover insights that would otherwise be inaccessible (Thorne, 2008). As a result of using this methodology I understood that as an interpretive instrument, it was important to take notes throughout the entire research process. I did this after every interview, during conversations with committee members, and during the data analysis process. I reviewed my notes to consider how I as the researcher utilized use of self during participant interviews to see if there were any potential implications for use of self in research.

As a researcher with a critical ontological and epistemological foundation, I believe in subjectivity, and that researcher values inform all aspects of the research process. Therefore, I did not feel the need to have strict boundaries with research participants. Even though most of my interviews were completed in 60 minutes or less, I was intrigued to learn that as a researcher I used self to build a relationship with the participants I interviewed. I understood the need to develop some trust in the researcher and the interview process so that practitioners would feel more comfortable answering interview questions honestly and openly. Therefore, if they asked about my experience, what the research project aimed to do, or what drove me to ask the specific research questions I answered them openly. In addition, before every interview, I took a few minutes to get to know each person I interviewed. I asked about the impact of COVID on their work, and shared genuine interest in their new professional realities. Participants were also curious about me. One social worker asked how I came to Portland State 
University from the east coast and how I got involved in conducting field education research.

Lastly, I thanked participants for their time at the end of every interview, and encouraged them to reach out if I could support their work in any way. I understood that the BIPOC field instructor community in Oregon was not large, and genuinely wanted to support the important work being done by my peers. Through my approach, which decentered the researcher as the expert and embraced self-disclosure, I felt an easy back and forth with many I interviewed. I also believe practitioners felt more secure engaging in the research project because they knew a little about me and my motivations. This connects with what interviewees shared about self-disclosure being necessary for feelings of safety in the worker-client relationship.

Because the present study takes a close look at race and use of self, race also factored into my use of self. Race entered the conversation immediately (sometimes before the interview started) and created an opening for interviewees and I to learn about each other's experiences. Participants and I talked explicitly about being in Oregon and what it felt like to be a racialized person in this place, we talked about cultural references, and the need for more BIPOC perspectives in social work education. In my notes, there is repeated mention of "us" and "we" because it came up so often when the field instructors I interviewed were speaking about the experience of "us" historically racially marginalized peoples. I also reflected their sentiments and used "us" and "we" when they did so. I even had two people who grew up in the same city that I did say that they were especially happy to participate because we were from the same town. 
I believe the biggest implications of this study on researcher use of self is this: just as qualitative researchers are interested in participant stories, participants are curious about researchers. Therefore, I encourage researchers to use self through self-disclosure and finding areas of common ground (such as race, motherhood, etc). This makes participants feel comfortable, and may increase the likelihood that they share their authentic experience. Social work researchers may also want to include sections on researcher use of self in their reports and write-ups to normalize use of self as an aspect of qualitative research.

A great example of how researcher use of self benefitted this project is that one participant honored me with a personal story then shared that it was not a story many knew; yet, she felt comfortable sharing it with me, a researcher. To me, this indicates the value of researchers actively using self in the research process to build relationships with participants. In doing so, they can garner more information about participant realities in the hopes of pushing a social justice agenda forward.

\section{Limitations}

Though this study offers some unique contributions to the literature on use of self, there are also some limitations. One limitation is that there are multiple other intersecting social groupings that inform BIPOC perspectives, and it is not a monolithic experience. So to be clear, I hope to expand knowledge around BIPOC experiences of use of self, and not to generalize the perspectives of all BIPOC peoples. Therefore, there may be other identity categories which inform how social workers use self. These categories may be intersect and also be a significant contributor to BIPOC use of self, and may include 
differential racial/ethic group experiences, cultural norms as well as client perceptions of the worker's ability, age, sexual orientation etc.

Another study limitation is that prior conceptualizations of use of self may have informed the language and my thinking on use of self. For example terms such as 'selfdisclosure' and the western individualistic conceptualization of self. My analysis and questions may have been different if self was conceptualized as communal, and not individualistic.

The next limitation for this study is that race and its effects continue to shift over time and this project speaks to one moment in time; it is not a longitudinal examination. Therefore, the effects of race and racism on use of self will continue to shift, and should be continually examined. Lastly, this research was conducted in Oregon which is a predominantly White state whose constitution included racist language until 2002. As a result, BIPOC social worker experiences may differ in a more racially/culturally/ethnically diverse state.

\section{Areas of Future Study}

Future research can explore how clients perceive the worker's use of self and its effects on their change process. The present study was not inclusive of the client experience but focused on how social workers use self in practice. Future research can examine how the self of the worker is received by the client, and to hear from the client perspective on how worker use of self affected their progress. It would also be useful to explore what use of self would look like if it was seen outside of the western individualized context. This would be beneficial as study findings indicate that there are 
factors outside of the self that affect the worker-client relationship, specifically social constructions around race and agency context. Therefore, it would be useful to study other micro, mezzo and macro factors that influence worker use of self which then informs the worker-client relationship.

Another future area of study is to examine how field instructors use self in supervision with students. This study centered the worker-client dyad, but use of self may shift if a social worker is in a mentorship-focused relationship with a student. In a different role (supervisor), use of self, might present itself differently, and be used for different purposes. In addition, it could be useful to more closely examine the agency context as it relates to use of self. Using a strengths-based approach, future studies can explore specific steps agencies have, and can take, to encourage worker use of self so that their client needs are met, and workers feel more fulfilled. In the social work field, burnout is common. Thus, more information about what agencies can do differently to support worker use of self to decrease worker burnout, and increase longevity in the field.

Next, it could be interesting to connect the literature on reflexivity and power to use of self. Because the self of the social worker is key to their practice, it would be helpful to study the specific ways power-sharing informs use of self. Given that the social work literature is increasingly discussing reflexivity in addition to self-awareness, there is space to consider how these approaches intersect, and to what effect.

Lastly, the COVID-19 pandemic forced many social work practitioners to work from home. I believe this could further complicate traditional notions of use of self because workers and clients had intimate access into each other's homes and personal 
lives in ways they did not have before. Especially for practitioners who were more resistant to self-disclosure, it would be fascinating to explore how COVID-19 has shifted, expanded, or generally influenced the ways they think about, and apply use of self.

\section{Conclusion}

The social work profession increasingly reflects the diversity of the general population. However, the field still struggles to accept that race and racism is central to the practice experience of BIPOC social workers. This dissertation highlighted the subjugated knowledge of racialized social workers as it pertains to use of self in practice. After interviewing 27 social workers about use of self and practice, findings indicate that race and racism affect perceptions of using self, and informed the 'self' that was utilized to advance client change. Future research is necessary to learn about use of self from the client perspective, and other micro, mezzo and macro factors that inform worker use of self. I am hopeful this project contributes to uplifting BIPOC perspectives in social work education and social work practice, and helps move forward conversations about race and practice. 


\section{REFERENCES}

Abrams, L. S., \& Moio, J. A. (2009). Critical race theory and the cultural competence dilemma in social work education. Journal of Social Work Education, 45(2), 245-261.

Alexander, F., \& French, T.M. (1946). Psychoanalytic therapy: Principles and application. Ronald Press.

Anastas, J. W. (2014). The science of social work and its relationship to social work practice. Research on Social Work Practice, 24(5), 571-580. doi: 10.1177/1049731513511335.

Anderson, S. C., \& Mandell, D. L. (1989). The use of self-disclosure by professional social workers. Social Casework, 70(5), 259-267.

Armour, M. P., Bain, B., \& Rubio, R. (2004). An evaluation study of diversity training for field instructors: A collaborative approach to enhancing cultural competence. Journal of Social Work Education, 40(1), 27-38.

Aponte, H. J., \& Winter, J. E. (1987). The person and practice of the therapist: Treatment and training. In Baldwin M. \& Satir, V. (Eds.), The Use of Self in Therapy (pp. 85-111). The Haworth Press

Arnd-Caddigan, M., \& Pozzuto, R. (2008). Use of self in relational clinical social work. Clinical Social Work Journal, 36(3), 235-243.

Ashforth, B. E., \& Mael, F. (1989). Social identity theory and the organization. Academy of management review, 14(1), 20-39.

Ashley, W., Santracruz-Cervantes, S., \& Castro, T. K. (2016). Professional conflict in social 
worker development: Transdisciplinary challenges for women of color. Reflections: Narratives of Professional Helping, 22(1), 11-16.

Badwall, H. K. (2015). Colonial encounters: Racialized social workers negotiating professional scripts of Whiteness. Intersectionalities: A Global Journal of Social Work Analysis, Research, Polity, and Practice, 3(1), 1-23.

Baldwin Jr, D. C. (1987). Some philosophical and psychological contributions to the use of self in therapy. In Baldwin M. \& Satir, V. (Eds.), The Use of Self in Therapy (pp. 27-44). The Haworth Press

Barnes, R. (1990). Race consciousness: The thematic content of racial distinctiveness in critical race legal scholarship. Harvard Law Review, 103, 1864-1871.

Bell Jr, D.A. (1979). Brown v. Board of Education and the interest-convergence dilemma. Harv. L. Rev., 93, 518-533

Bell Jr, D.A (1995) Who's Afraid of Critical Race Theory? University of Illinois Law Review, Vol. 1995, 893-910.

Berman-Rossi, T. \&amp; Miller, I. (1994). African-Americans and the Settlements during the late nineteenth and early twentieth centuries. Social Work with Groups, 17(3), 77-95.

Bernard, H. S. (2005). Countertransference: The evolution of a construct. International Journal Of Group Psychotherapy, 55, 151-160.

BIPOC Project (n.d). About us. https://www.thebipocproject.org/about-us

Black, J. E., Maki, M. T., \& Nunn, J. A. (1997). Does race affect the social work student-field instructor relationship? The Clinical Supervisor, 16(1), 39-54.

Boud, D. (1999). Avoiding the traps: Seeking good practice in the use of self assessment and reflection in professional courses. Social Work Education, 18(2), 121-132. 
Braun, V. \& Clarke, V. (2012). Using thematic analysis in psychology. Qualitative Research in Psychology, 3, 77-101.

Brewer, M. B. (1999). The psychology of prejudice: Ingroup love and outgroup hate?. Journal of social issues, 55(3), 429-444.

Brewer, K. M., Harwood, M. L., McCann, C. M., Crengle, S. M., \& Worrall, L. E. (2014). The use of interpretive description within Kaupapa Māori research. Qualitative health research, 24(9), 1287-1297.

Brown, R. (2000). Social identity theory: Past achievements, current problems and future challenges. European journal of social psychology, 30(6), 745-778.

Calmore, J. O. (1995). Critical race theory, Archie Shepp, and fire music: Securing an authentic intellectual life in a multicultural world. In Crenshaw, K., Gotanda, N. Peller, G. \& Thomas, K., Critical race theory: Key writings that formed the movement (pp. 315-329). The New Press

Chau, K. L. (1990). A model for teaching cross-cultural practice in social work. Journal of social work education, 26(2), 124-133.

Clark, M. I., Spence, J. C., \& Holt, N. L. (2011). In the shoes of young adolescent girls: Understanding physical activity experiences through interpretive description. Qualitative research in sport, exercise and health, 3(2), 193-210.

Coady, N.F. \& Wolgien, C.S. (1996). Good therapists' views of how they are helpful. Clinical Social Work Journal, 24(3):311-322.

Collins, P. H. (2000). Black feminist thought: Knowledge, consciousness, and the politics of Empowerment, 2nd ed.. Routledge.

Collins, P. H. (2000). Black feminist epistemology. In Black feminist thought: Knowledge, 
consciousness, and the politics of empowerment, 2nd ed. (p 251-6, 266-71). Routledge

Constance-Huggins, M. (2012). Critical race theory in social work education: A framework for addressing racial disparities. Critical Social Work, 13(2), 1-16.

Corbin, J. \& Strauss, A. (2008). Basics of qualitative research: Techniques and procedures for developing grounded theory (3rd ed). Sage.

Council on Social Work Education (2017). Profile of the social work workforce.

https://www.cswe.org/Centers-Initiatives/Initiatives/National-Workforce-Initiative/SWWorkforce-Book-FINAL-11-08-2017.aspx

Council on Social Work Education (2018). 2017 statistics on social work education in the United States. https://www.cswe.org/CMSPages/GetFile.aspx?guid=44f2c1de-65bc-41fb-be38f05a5ab

ae96d

Cox, S., \& Gallois, C. (1996). Gay and lesbian identity development: A social identity perspective. Journal of Homosexuality, 30(4), 1-30.

Crenshaw, K., Gotanda, N., Peller, G., \& Thomas, K. (1995). Critical race theory: The key writings that formed the movement. New York, NY: The New Press

Crotty, M. (1998). The Foundations of Social Research. Sage

Delgado, R., \& Stefancic, J. (Eds.). (2000). Critical race theory: The cutting edge. Temple University Press

Dewane, C. J. (2006). Use of self: A primer revisited. Clinical Social Work Journal, 34(4), 543-558.

Denzin, N. K., \& Lincoln, Y. S. (Eds.). (2005). The Sage handbook of qualitative research (3rd ed.). Sage. 
Dewees, M. (2008). Building cultural competence for work with diverse families. Journal of Ethnic and Cultural Diversity in Social Work, 9(3-4), 33-51. doi:10.1300/J051v09n03_02.

D’Cruz, H., Gillingham, P., \& Melendez, S. (2007). Reflexivity, its meanings and relevance for social work: A critical review of the literature. The British Journal of Social Work, 37(1), 73-90.

Dubois, W.E.B. (1999). The souls of black folk (H.L. Gates \& T.H. Oliver, Eds). W.W. Norton \& Company.

Fook, J. (2002). Social Work: Critical Theory and Practice. Sage

Foucault, M. (1977). Power/knowledge: Selected interviews and other writings. (C. Gordon, Ed.). Pantheon Books.

Ganzer, C. (2007). The use of self from a relational perspective. Clinical Social Work Journal, $35(2), 117-123$.

Gordon, J., \& Dunworth, M. (2017). The fall and rise of 'use of self'? An exploration of the positioning of use of self in social work education. Social Work Education, 36(5), 591-603.

Gotanda, N. (1995). A critique of "our Constitution is color-blind." In Crenshaw, K., Gotanda, N. Peller, G. \& Thomas, K., Critical race theory: Key writings that formed the movement (pp. 315-329). The New Press

Griffith, M. S. (1977). The influences of race on the psychotherapeutic relationship. Psychiatry, 40(1), 27-40.

Haney-Lopez, I.F. (1994). The social construction of race. In R. Delgado (Ed.), Critical race theory: The cutting edge (p. 191-203). Temple University Press. 
Hesse-Biber, S.N. (2014). Feminist research practice: A primer (2nd ed). Sage

Hesse-Biber, S.N. (2017). The practice of qualitative research (3rd ed). Sage

Heydt, M. J., \& Sherman, N. E. (2005). Conscious use of self: Tuning the instrument of social work practice with cultural competence. Journal of Baccalaureate Social Work, 10(2), 25-40.

Hornsey, M. J. (2008). Social identity theory and self-categorization theory: A historical review. Social and Personality Psychology Compass, 2(1), 204-222.

Hounmenou, C. (2012). Black settlement houses and oppositional consciousness. Journal of Black Studies, 43(6), 646-666.

Howell, K.E. (2013). The philosophy of methodology. Sage.

Huddy, L. (2001). From social to political identity: A critical examination of social identity theory. Political psychology, 22(1), 127-156.

Hughes, D. L., \& DuMont, K. (1993). Using focus groups to facilitate culturally anchored research. American Journal of Community Psychology, 21(6), 775-807.

Hunt, M. R. (2009). Strengths and challenges in the use of interpretive description: reflections arising from a study of the moral experience of health professionals in humanitarian work. Qualitative health research, 19(9), 1284-1292.

Hylton, K. (2012). Talk the talk, walk the walk: Defining critical race theory in research. Race Ethnicity and Education, 15(1), 23-41.

Jacobson, W. B. (2001). Beyond therapy: Bringing social work back to human services reform. Social Work, 46(1), 51-62.

Jamieson, D. W. \& Davidson, J. E. (2019). Advancing Thinking and Practice on Use of Self. Organization Development Journal, 37(1), 39-54. 
Janack, M. (1997). Standpoint epistemology without the "standpoint"?: An examination of epistemic privilege and epistemic authority. Hypatia, 12(2), 125-139.

Jenkins, R. (2008). Social identity (3rd ed.). Routledge.

Jones, E. E. (1978). Effects of race on psychotherapy process and outcome: An exploratory investigation. Psychotherapy: Theory, Research \& Practice, 15(3), 226-236.

Kalengayi, F. K. N., Hurtig, A. K., Ahlm, C., \& Ahlberg, B. M. (2012). "It is a challenge to do it the right way": an interpretive description of caregivers' experiences in caring for migrant patients in Northern Sweden. BMC health services research, 12(1), 433.

Kaushik, A. (2018). Use of 'Self' in Social Work: Some Reflections. The Indian Journal of Social Work, 79(4), 403-414.

Kincheloe J.L. \& McLaren, P. (2005). Rethinking critical theory and qualitative research. In N.K Denzin \& Y.S. Lincoln (Eds.), The sage handbook of qualitative research (3rd Ed) (pp. 303-342). Sage Publications

Kolivoski, K.M, Weaver A., \& Constance-Huggins M. (2014). Critical race theory: Opportunities for application in social work practice and policy. Families in Society: The Journal of Contemporary Social Services 95(4), 269-276. DOI:

$10.1606 / 1044-3894.2014 .95 .36269$

Kondrat, M. E. (1999). Who is the "self" in self-aware: Professional self-awareness from a critical theory perspective. Social Service Review, 73(4), 451-477.

Ladson-Billings, G. (1998). Just what is critical race theory and what is it doing in a 'nice' field like education? International Journal of Qualitative Studies in Education, 11, 7-24.

Ladson-Billings, G. (2000). Racialized discourses and ethnic epistemologies. In Denzin, N.A. \& 
Lincoln, Y.S. (Eds.), The handbook of qualitative research (189-213). London, UK: Sage.

Lam, C. M., Wong, H., \& Leung, T. T. F. (2006). An unfinished reflexive journey: Social work students' reflection on their placement experiences. British Journal of Social Work, 37(1), 91-105.

Leary, K. (1997). Race, self-disclosure, and “forbidden talk": Race and ethnicity in contemporary clinical practice. The Psychoanalytic Quarterly, 66(2), 163-189.

Leary, K. (2000). Racial enactments in dynamic treatment. Psychoanalytic Dialogues, 10(4), 639-653.

Leary, K. (2007). Racial insult and repair. Psychoanalytic Dialogues, 17(4), 539-549.

Liechty, J. (2018). Exploring Use of Self: Moving Beyond Definitional Challenges. Journal of Social Work Education, 54(1), 148-162.

Maidment, J., \& Cooper, L. (2002). Acknowledgement of client diversity and oppression in social work student supervision. Social Work Education, 21(4), 399-407.

Mandell, D. (2008). Power, care and vulnerability: Considering use of self in child welfare work. Journal of Social Work Practice, 22(2), 235-248.

Mehrotra, G. R., Hudson, K. D., \& Self, J. M. (2019). A critical examination of key assumptions underlying diversity and social justice courses in social work. Journal of Progressive Human Services, 30(2), 127-147.

Merrick, E. (1999). An exploration of quality in qualitative research: Are "reliability" and “validity" relevant? In M. Kopala \& L. Suzuki (Eds.), Using qualitative methods in psychology (pp. 25-36). Thousand Oaks, CA: Sage Publications

McRoy, R. G., Freeman, E. M., Logan S. L., \& Blackmon, B. (1986). Cross-cultural field 
supervision: Implications for social work education. Journal of Social Work Education, 22(1), 50-56.

Miehls, D., \& Moffatt, K. (2000). Constructing social work identity based on the reflexive self. British Journal of Social Work, 30(3), 339-348.

Mohanty, C. T. (2003). "Under western eyes" revisited: Feminist solidarity through anticapitalist struggles. Signs: Journal of Women in culture and Society, 28(2), 499-535.

Morrow, R.A. (1994). Critical theory, poststructuralism, and critical realism: Reassessing the critiques of positivism. In Current Perspectives in Social Theory, 14, 27-51

Morrow, S. L. (2005). Quality and trustworthiness in qualitative research in counseling psychology. Journal of counseling psychology, 52(2), 250-260

Murphy, A. L., Martin-Misener, R., Kutcher, S. P., O’Reilly, C. L., Chen, T. F., \& Gardner, D. M. (2016). From personal crisis care to convenience shopping: an interpretive description of the experiences of people with mental illness and addictions in community pharmacies. BMC health services research, 16(1), 569.

Murphy, M. J., Faulkner, R. A., \& Behrens, C. (2004). The effect of therapist-client racial similarity on client satisfaction and therapist evaluation of treatment. Contemporary Family Therapy, 26(3), 279-292.

Nesdale, D. (1999). Social identity and ethnic prejudice in children. Psychology and society, 92-110.

Oliver, C. (2012). The relationship between symbolic interactionism and interpretive description. Qualitative Health Research, 22(3), 409-415.

Olsen, N. R., Bradley, P., Lomborg, K., \& Nortvedt, M. W. (2013). Evidence based practice in clinical physiotherapy education: a qualitative interpretive description. BMC medical 
education, 13(1), 52.

Ortiz, L., \& Jani, J. (2010). Critical race theory: A transformational model for teaching diversity. Journal of Social Work Education, 46(2), 175-193.

Price, M. (1997), The power of enactments and the enactment of power. Paper presented at the meeting of the American Psychoanalytic Association, New York.

Perdue, C.W., Dovidio, J.F., Gurtman, M.B., \& Tyler, R.B. (1990). Us and them: social categorization and the process of intergroup bias. Journal of Personality and Social Psychology, 59(3), 475.

Raines, J.C. (1996). Self-disclosure in clinical social work. Clinical Social Work Journal, 24(4), 357-375.

Razack, N. (2001). Diversity and difference in the field education encounter: Racial minority students in the practicum. Social Work Education, 20(2), 219-232.

Razack, N., \& Jeffery, D. (2002). Critical race discourse and tenets for social work. Canadian Social Work Review/Revue canadienne de service social, 19(2), p. 257-271.

Reinkraut, R. (2008). Moral awareness and therapist use of self. Journal of Pedagogy, Pluralism and Practice, 13, 1-17.

Reupert, A. (2007). Social worker's use of self. Clinical Social Work Journal, 35(2), 107-116.

Reupert, A. (2008). A trans-disciplinary study of the therapist's self. European Journal of Psychotherapy and Counseling, 10(4), 369-383.

Reupert, A. (2009). Students' use of self: Teaching implications. Social Work Education, 28(7), 765-777.

Rubin, H. J., \& Rubin, I. S. (2005). Qualitative interviewing: The art of hearing data. Sage.

Salas, L. M., Sen, S., \& Segal, E. A. (2010). Critical theory: Pathway from dichotomous to 
integrated social work practice. Families in Society, 91(1), 91-96.

Satir, V. (2013). The therapist story. In Baldwin M. \& Satir, V. (Eds.), The Use of Self in Therapy (pp. 17-25). The Haworth Press.

Schiele, J. H. (2007). Implications of the equality-of-oppressions paradigm for curriculum content on people of color. Journal of Social Work Education, 43(1), 83-100.

Schwandt, T.A (1997). Qualitative inquiry: A dictionary of terms. Thousand Oaks, CA: Sage.

Shadley, M. L. (1987). Are all therapists alike? Use of self in family therapy: A multidimensional perspective. Journal of Psychotherapy \& The Family, 3(1), 127-137.

Sheafor, B. W, \& Horejsi, C. R. (2003). Techniques and guidelines for social work practice (6th ed.). Allyn \& Bacon

Solórzano, D., \& Bernai, D. (2001). Examining transformational resistance through critical race theory and LatCRIT theory framework; Chicana and Chicano students in an urban context. Urban Education, 36(3), 308-342.

Stage, F.K. (2007). Answering critical questions using quantitative data. New Directors for Institutional Research, 133, 5-15. doi:10.1002/ir.200.

Stets, J. E., \& Burke, P. J. (2000). Identity theory and social identity theory. Social psychology quarterly, 224-237.

Tajfel, H. (1974). Social identity and intergroup behaviour. Information (International Social Science Council), 13(2), 65-93.

Tajfel, H. (1982). Social psychology of intergroup relations. Annual review of psychology, 33(1), 1-39.

Tajfel, H., \& Turner, J. C. (1986). The social identity theory of intergroup behavior. In S. Worchel \& W G. Austin (Eds), Psychology of intergroup relations (2nd ed., pp. 7-24). 
Chicago, IL: Nelson-Hall

Taylor, E. (2009). The foundations of critical race theory in education: An introduction. In E.

Taylor, D. Gillborn \& G. Ladson-Billings (Eds.), Foundations of Critical Race Theory in Education (p. 1-13). Routledge

Thorne, S., Kirkham, S. R., \& MacDonald-Emes, J. (1997). Interpretive description: a noncategorical qualitative alternative for developing nursing knowledge. Research in nursing \& health, 20(2), 169-177.

Thorne, S., Kirkham, S. R., \& O'Flynn-Magee, K. (2004). The analytic challenge in interpretive description. International journal of qualitative methods, 3(1), 1-11.

Thorne S. (2008). Interpretive description: Qualitative research for applied practice. Left Coast Press

Turner, J. C., Hogg, M. A., Oakes, P. J., Reicher, S. D., \& Wetherell, M. S. (1987). Rediscovering The social group: A self-categorization theory. Cambridge, MA, US: Basil Blackwell.

United States Census Bureau (2018). Demographic turning points for the United States:

Population projections for 2020-2030.

https://www.census.gov/content/dam/Census/library/publications/2018/demo/P25_1144.p df

United States Census Bureau (2018). Quick facts: United States. https://www.census.gov/quickfacts/fact/table/US/PST045217

Varghese, R. (2016). Teaching to transform? Addressing race and racism in the teaching of clinical social work practice. Journal of Social Work Education, 52(S1), S134-S147.

Wang, D. (2012). The use of self and reflective practice in relational teaching and adult learning: 
A social work perspective. Reflective Practice, 13(1), 55-63.

Weiner, M. F. (1983). Therapist disclosure: The use of self in psychotherapy (2nd ed.). University Park Press.

Williams, C.C. (2006). The epistemology of cultural competence. Families in Society: The Journal of Contemporary Social Services, 87(2), 209-220.

Yosso, T., Smith, W., Ceja, M., \& Solórzano, D. (2009). Critical race theory, racial microaggressions, and campus racial climate for Latina/o undergraduates. Harvard Educational Review, 79(4), 659-691. 


\section{APPENDICES}

\section{Appendix A Recruitment Emails}

Dear [Faculty/Field Team],

I am pleased to be working on an exploratory project to assess how field instructors of color engage 'use of self' in their practice. The research questions guiding this project are:

- What are the components of use of self, as defined by BIPOC social workers?

- How have they used self in their practice and to what effect?

- How do issues of race and racism affect their perceptions of using self in practice contexts?

To explore these questions, 25-30 individual interviews will be held with social workers of color who supervise or have supervised, undergraduate or graduate-level social work students. I hope to recruit social workers of color with diverse racial/ethnic backgrounds, and who work in a range of settings, to share their perspectives and experiences.

In order to be eligible to participate, individuals must: 1) identify as a person of color or mixed race, 2) have served as or are eligible to serve as a field instructor for social work students. Do you know any field instructors who would qualify for the study and be interested in participating? If so, please have them contact me at gooding @ pdx.edu for more information and next steps. They will receive a $\$ 20$ honorarium for time and participation.

Thank you for your assistance with this project.

Best, Anita Gooding 
Dear [Field Instructors],

Hello! My name is Anita Gooding and I am a doctoral student at Portland State University in the School of Social Work. I am pleased to be working on an exploratory project to assess how field instructors of color engage 'use of self' in their practice, and received your name from [insert name] who thought you might be interested in participating.

The research questions guiding this project are:

- What are the components of use of self, as defined by BIPOC social workers?

- How have they used self in their practice and to what effect?

- How do issues of race and racism affect their perceptions of using self in practice contexts?

To explore these questions, 25-30 individual interviews will be held with social workers of color who supervise, or have supervised, undergraduate or graduate-level social work students. I hope to recruit social workers of color with diverse racial/ethnic backgrounds, and who work in a range of settings, to share their perspectives and experiences.

Are you willing and interested in being part of this study? In order to be eligible to participate, you must: 1) identify as a person of color or mixed race, 2) have served as or are eligible to serve as a field instructor for social work students.

Interviews will last 60-90 minutes and will focus on your perspectives on the field education process and your experiences as a social worker of color. Participants will receive a $\$ 20$ gift card honorarium for time and participation. Please also know that participation in this project is completely voluntary and there will be absolutely no consequences to you in any way if you choose not to participate.

If you are interested in being part of this project, have questions, and/or would like more information, please contact me at gooding@pdx.edu and I will be in touch with you to answer questions and/or to discuss next steps!

Thank you for your time and consideration!

Best, Anita Gooding 


\title{
Appendix B: Consent Form
}

\author{
Portland State University \\ Consent to Participate in Research
}

E(raced): Race and Use of Self Amongst BIPOC Social Workers

2020-2021

Introduction

You are being asked to participate in a research study that is being conducted by doctoral student Anita Gooding under Principal Investigator Dr. Gita Mehrotra, from the School of Social Work (SSW), at Portland State University (PSU) in Portland, Oregon. This research is studying perspectives and experiences of social workers of color who have served as field instructors for students, with a focus on issues of identity and practice.

You are being asked to participate in this study because you are a social worker of color in Oregon who has served or are eligible to serve as a field instructor. This form will explain the research study, and will also explain the possible risks and possible benefits to you. If you have any questions, please ask the study investigator.

What will happen if I decide to participate?

If you agree to participate in this project, you will be asked to be part of an interview that will last up to 90 minutes. The conversation will focus on how identity impacts your practice as well as your experiences of being a social worker of color and field instructor within your agency context and in Portland, OR. If you agree to participate, with your permission, we will audio-record the interview. You will also have the opportunity to review the interview transcript if you would like.

How long will I be in this study?

Participation in this study will take a total of 90 minutes maximum.

What are the risks or side effects of being in this study?

While there are often risks of stress, emotional distress, inconvenience and possible loss of privacy and confidentiality associated with participating in a research, this study involves minimal risk. The topics being explored in this study are topics related to your experiences that social workers may converse on quite regularly with peers, field instructors, and faculty members. However, this study could elicit more personal and deeper explorations of these topics. To ensure confidentiality and privacy, the Investigator will take care that no one overhears the participants at the time of the interview by holding it in a comfortable, quiet, private space in which there is plenty of separation and privacy from others. If any questions do for some reason elicit unpleasant memories or situations, etc. you always have the right to take a break, skip a question, or 
withdraw from the study at any point without penalty, and without in any way affecting our relationship, your relationship with the Social Work program, or your University partnerships.

What are the benefits to being in this study?

There is no direct benefit to participants for being a part of this study, however this project will contribute to greater understanding of the needs, unique challenges, and factors that contribute to success for social workers of color in field education and could help inform the development of a larger study on these topics as well. Through the interview you may also gain added clarity and insight into your own experiences that may shape your future work.

How will my information be kept confidential?

Interviews will be held in a private, confidential location. With permission, interviews will be recorded on a digital recorder in their entirety. The audio file will be transferred to a password-protected computer immediately after the interview (before the Investigator leaves the site) and will be saved to a password-protected folder on the computer. In addition, interviews will be transcribed as soon as possible after they take place. Only the Investigators will have access to the transcribed interviews and to the audio files. No identifying information will be included in the transcripts. Interview transcripts will be assigned a code that will be kept separately from the audio file. Audio files and the code list will be destroyed 3 years following completion of the study

Remote interviews will occur when in-person interviews are not possible to prevent COVID-19 exposure and transmission. Remote interviews will be conducted via Zoom. Zoom interviews will be password protected. If a Zoom interview is not possible or you prefer the phone, a telephone interview will be done instead. For both Zoom and telephone interviews, the interviewer will email the consent prior to the interview. If you decide NOT to participate in the interview you would reply with "no" and we would not contact you again. If you decide you DO want to participate in the interview, reply with "yes." We will then get started with the interview.

For interviews via Zoom or telephone, interviewers will be in a private location where they will not be overheard during the time of the interview to ensure confidentiality. Prior to beginning the interview, respondents will be given time to move to a location where they will not be overheard. They will also verbally consent to the audio being recorded. Recordings and forms will be stored in an electronic folder where only the research team has access. After all the interviews are completed, recordings will be sent to a transcriptionist. To maintain confidentiality, identifying information will be stored separately from the transcripts.

In any publications or presentations regarding this study, interviews will be identified by participant number or using a pseudonym to protect participants confidentiality. No identifying information regarding field sites or staff of agencies will be shared. If 
agencies are referenced in publications/presentations, they will only be referenced by the type of site such as "non-profit" or "state agency".

Portland State University Institutional Review Board (IRB) that oversees human subject research and/or other entities may be permitted to access your records, and there may be times when we are required by law to share your information. It is the investigator's legal obligation to report child abuse, child neglect, elder abuse, harm to self or others or any life-threatening situation to the appropriate authorities, and; therefore, in such circumstance your confidentiality will not be maintained.Your name or any identifiable information will not be used in any published reports about this study.

Will I be paid for taking part in this study?

You will receive a $\$ 20.00$ gift card upon completion of the interview as an honorarium for your participation.

Can I stop being in the study once I begin?

Your participation in this study is completely voluntary. You have the right to choose not to participate or to withdraw your participation at any point in this study without penalty or loss of benefits to which you are otherwise entitled.

Whom can I call with questions or complaints about this study?

If you have any questions, concerns or complaints at any time about the research study, the Principal Investigator, Dr. Gita Mehrotra will be glad to answer them at (503) 7255011 or via email at gmehrotra@pdx.edu.

Whom can I call with questions about my rights as a research participant?

If you have questions regarding your rights as a research participant, you may call the PSU Office for Research Integrity at (503) 725-2227 or 1(877) 480-4400. The ORI is the office that supports the PSU Institutional Review Board (IRB). The IRB is a group of people from PSU and the community who provide independent oversight of safety and ethical issues related to research involving human participants. For more information, you may also access the IRB website at https://sites.google.com/a/pdx.edu/research/integrity.

\section{CONSENT}

You are making a decision whether to participate in this study. Your signature below indicates that you have read the information provided (or the information was read to you). By signing this consent form, you are not waiving any of your legal rights as a research participant.

You have had an opportunity to ask questions and all questions have been answered to your satisfaction. By signing this consent form, you agree to participate in this study. A copy of this consent form will be provided to you. 
Name of Adult Subject (print)

INVESTIGATOR SIGNATURE

This research study has been explained to the participant and all of his/her questions have been answered. The participant understands the information described in this consent form and freely consents to participate.

Name of Investigator/ Research Team Member (type or print)

(Signature of Investigator/ Research Team Member)

Date 


\section{Appendix C: Interview Guide}

1) What drew you to the social work profession?

2) What keeps you in the profession?

3) Use of self is defined as the social worker's instrument, and is when a worker pulls from their personal characteristics to build relationships with clients and facilitate client change. Please think about a time where you had a particularly meaningful interaction with a client. What parts of who you are did you use to help facilitate change? Take your time.

a) Why did you use those parts of yourself?

b) What benefits have you seen for your practice and for the clients you work with when you use those parts of yourself? (Provide examples)

c) What disadvantages (if any) have you experienced when you use those parts of yourself? (Provide examples)

d) What enables you to use self?

e) How does being in Portland affect your use of self as a BIPOC person? How does it compare to other places you have lived? (Provide examples)

f) How does the culture at your agency affect your use of self?

4) What effect does race (yours or your client's) have on your ability to use parts of who you are to facilitate client change? (Provide examples)

a) What has it been like to work with members of your own community and/or people of color compared with Whites? (Provide examples)

b) How does race affect the way you practice social work?

i) How does your racial identity impact the way you think of your professional identity as a social worker? Is there a tension for you?

5) Is there anything else you wish to share? 


\section{Appendix D: Demographic Form}

Participant \#

E(raced): Race \& Use of Self Amongst BIPOC Social Workers

Demographic Form

\begin{tabular}{|l|l|}
\hline Participant name & \\
\hline $\begin{array}{l}\text { How long have you been practicing social } \\
\text { work? }\end{array}$ & \\
\hline Primary field(s) of practice & \\
\hline Current Organization(s) & \\
\hline Primary communities served by the \\
organization(s)?
\end{tabular}




\begin{tabular}{|l|l|}
\hline & \\
\hline Any other salient identities you want to share? & \\
\hline Additional Notes/Comment & \\
\hline
\end{tabular}

